\title{
Equivalent Computational Models and Deflection Calculation Methods of Box Girders with Corrugated Steel Webs
}

\begin{abstract}
This study found that it is improper to use equivalent concrete webs (ECWs) to replace corrugated steel webs (CSWs) in the MIDAS Civil. To reflect the mechanical performance difference of CSWs in different directions, a more precise theoretical model, the assimilated orthotropic plate (AOP), is presented to simulate CSWs. 3D Finite element analysis demonstrates that the AOP model can yield a more precise description of CSWs compared with the ECW model in MIDAS. In addition, this paper presents a unified calculation method for bending deformation suitable for the analysis of beams with equal-area or variable-area cross-sections, in which the non-prismatic beam is made equivalent to the prismatic beam by introducing the concept of equivalent inertia moment. Additionally, the formula of shear deformation in a non-prismatic box girder with CSWs is also derived with Timoshenko beam theory. These derived formulas for non-prismatic box girder with CSWs agree well with the numerical and measured data.
\end{abstract}

Key words: non-prismatic box girder; corrugated steel webs; equivalent flat concrete webs; assimilated orthotropic plates; bending deformation; shear deformation

\section{Introduction}

As a new type of composite structure, box girders with CSWs originated in France in the 1980s and were soon after widely applied in Japan. In the last 15 years, PC girders with CSWs have been vigorously promoted in China [1]. However, there is no specialized 3D finite element software or universal standard method for this new structure in China. Generally, the finite element software MIDAS Civil is adopted to check and analyze the design of such structures. As a professional design software application, MIDAS Civil has been widely used in South Korea, China and other countries (more than 150 countries). The spatial beam element is adopted to simulate the composite box girder with CSWs in MIDAS Civil. In the program, the folded steel webs are equivalent to the usual concrete flat webs according to the principle of equivalent stiffness. This program uses two basic assumptions: 1) The ECWs bear all vertical shear force in the section; 2) Only the area of the ECWs is included in the calculation of the effective shear area of the cross section; namely, the shear stiffness and the shear deformation of the concrete flanges are ignored. These assumptions are obviously inappropriate for non-prismatic box girders with CSWs. The reasons for this are as follows: The inclined bottom concrete flange will share a significant part of the shearing force; therefore, the shearing force of the web calculated by MIDAS are larger than the accurate results if the shear capacity of the concrete flanges is ignored. Second, the ECWs are nearly 6 times (the ratio of the elastic modulus of steel to that of concrete) the thickness of the CSWs; thus, the shear stress in the ECWs calculated by MIDAS is only 1/6 of the stress of the CSWs. In addition, the accordion effect of CSWs cannot be reflected in the ECW model. Because the ECW beam model includes many assumptions and cannot accurately reflect the mechanical behavior of the CSWs, seeking a reasonable, simple and accurate model is needed to reflect the features of CSWs represents an urgent matter.

Accordingly, a comparison of the solid model in ABAQUS (CSW model) and the beam model in MIDAS (ECW model) is presented, and the 3-D CSW solid model is used as a standard 
reference model to evaluate the accuracy of the stress and deformation of the ECW beam model. However, the space effect and analysis of local stress cannot be analyzed using the MIDAS beam model. To reflect the characteristics of the CSWs more exactly, a more accurate simulation model-AOPs model - is developed. In this paper, a long-span non-prismatic box girder bridge with CSWs is chosen as the project background. The solid models of CSW, ECW and AOP are established in ABAQUS. Through comparative analysis and study of the three models, a more reasonable equivalent analysis model of the CSWs is presented. In addition, the calculation and distribution of shear stress in the non-prismatic box girder with CSWs will be quite different from the prismatic member; the calculated shear stress in the webs would be overly conservative if the shear capacity of concrete flanges was ignored. Compared with the ordinary prestressed concrete box girder, the shear stiffness of the composite box girder with CSWs is substantially smaller [2] (approximately $8 \%$ of the former), which means that the shear deformation in this structure is also been quite pronounced. The mechanical performances of the non-prismatic box girder with CSWs have received little scientific attention in previous studies. Many scholars thoroughly studied prismatic I- or box girders with CSWs. The shear stress and shear deformation were usually studied via experimental and finite element methods but lacked an analytical expression for computing the stress and deformation of the non-prismatic box girder with CSWs. Therefore, the theoretical study of the basic mechanical properties of a non-prismatic beam with CSWs represents a research direction worthy of academic attention.

Current research progress on CSWs is now briefly discussed. Because shear bucking is a key issue in the design of such a structure, many scholars have focused on the global and local buckling of prismatic I- or box girders with CSWs [3-16]. Hassaneinet and Zevallos [17-18] have done some theoretical research, first on the shear buckling behavior of tapered bridge girders with CSWs, and put forward a design strength formula for the tapered CSWs. In addition, some scholars have conducted basic research on shear stress and shear deformation related to this study. Through experimental study and theoretical analysis, Hamilton [3] and Johnson [19] found that shear forces are resisted mainly by the CSWs, and the longitudinal bending moment is resisted mostly by axial forces in the concrete flanges. Shitou et al., [20] experimentally determined that the load sharing ratio of the CSWs to shear increased with crack propagation in the concrete flanges but decreased when the steel reached the yielding strength. Machimdamrong et al., [21] asserted that errors result when the Euler-Bernoulli beam theory is applied to stress and deformation analysis of box girder with CSWs. A more refined beam theory that accounts for shear deformation is derived by the application of the variational principle. Based on the displacement field assumption, internal force equilibrium equations, and the deformation compatibility condition, He et al., [22] presented the elastic bending theory by considering shear deformation for a composite bridge with CSWs.

From the above-mentioned studies, it can be concluded that studies on the shear stress and deflection of non-prismatic box girders with CSWs in the elastic stage remain insufficient. However, considering economic and construction feasibility, the non-prismatic box girder is one of the most popular structure types in bridge design. The mechanical behaviour of the non-prismatic beam is very different from that of the prismatic beam owing to the effect of variable section. The ultimate bearing capacity of this structure is dominated by the shear buckling failure of the CSWs. However, a bridge is usually in the elastic stage during construction and service. The control of vertical deflection in the elastic stage is also crucial to satisfy the 
requirements of the servicing limit states in bridge design. Accordingly, the static analysis of the non-prismatic box girders with CSWs at the elastic stage is significant in theory and practice.

\section{Comparison of multiple equivalent analytical models of CSWs}

\subsection{The project background}

The Fenghua River bridge, which is one of the longest span non-prismatic box girders with CSWs under construction in China, was selected as the study object. The superstructure of the Fenghua River bridge is a three-span PC composite continuous box girder with a main span of 160 $\mathrm{m}$. The cantilever construction method is used, and the main girder is divided into many sections and steps of pouring and prestressing. Because balanced cantilever construction is adopted, the bridge must undergo the longest cantilevered stage, which is the most adverse load case during the construction stage. Therefore, the 80-m cantilever beam in the largest single-cantilever state of the middle span was chosen for this study, and the dimensions of the section are shown in Fig. 1

8000

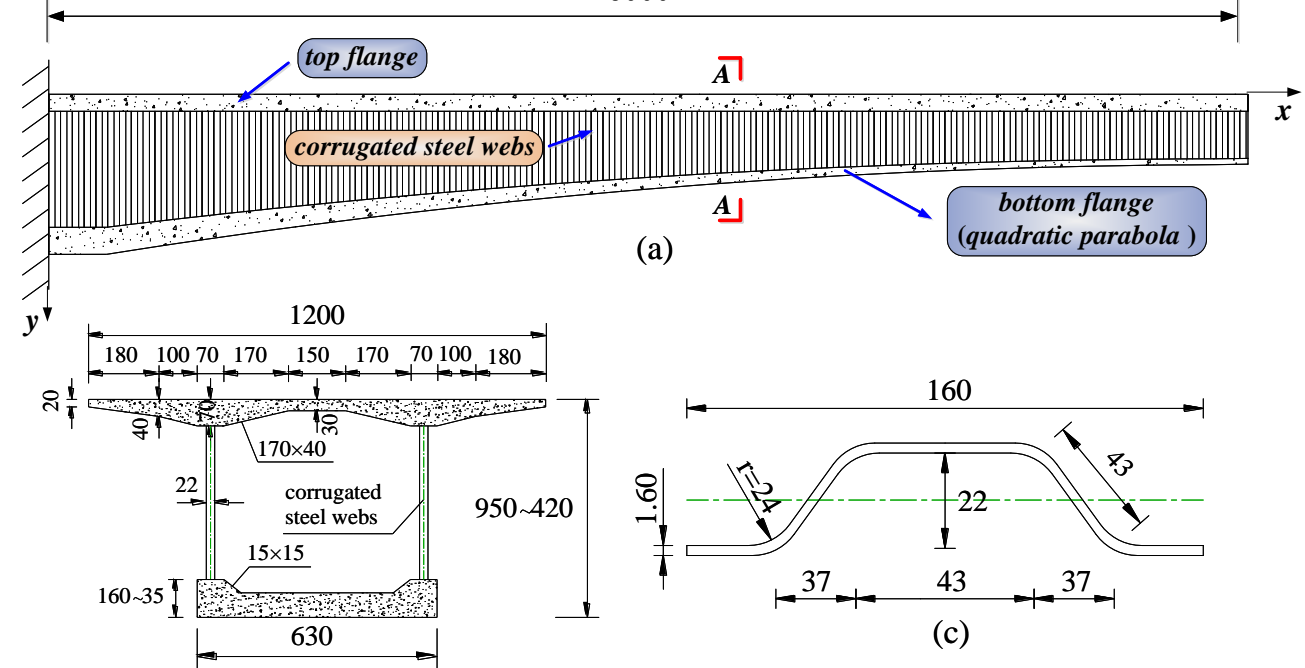

(b) A-A section

Fig.1. The dimensions of the section of the 80-m cantilever beam (a) elevation (b) cross-section (c) CSWs (unit: $\mathrm{cm}$ )

\subsection{Discussion of the equivalent model of CSW in MIDAS Civil}

\subsubsection{The FE model of MIDAS Civil and ABAQUS}

As mentioned above, the spatial beam element is adopted to simulate the box girder with CSWs in MIDAS Civil. The CSWs are replaced with ECWs according to the conversion elastic modulus of steel and concrete, as shown in Fig. 2a. For the beam model of the box girder with CSWs, only the contribution of the concrete flanges is considered in the bending stiffness, as shown in Fig. 3b. And only the area of ECWs is assumed as the effective shear area. The user can choose whether or not to consider shear deformation in the calculation of beam deflection by the option button. Under the assumption of quasi-plane section, the normal stress at the concrete flanges presents linear distribution, as shown in Fig. 3c. The ECWs are assumed to bear all vertical shear force in section and the shear stress in the thin CSWs presents an even distribution, as shown in Fig. 3c. To evaluate the computation results obtained by MIDAS Civil, two 3D finite element models were established in ABAQUS, as shown in Fig. 2 b and Fig. 2c. Among them, model-2 is highly similar to model-1, except that the former is a more accurate solid 
model, and the latter was established based on the beam element. By comparing model-1 and model-2, some assumptions in the analysis module of MIDAS Civil can be verified. Model-3 is established in accordance with the actual dimensions of the bridge and can be used to validate the results when the ECWs replace the CSWs in MIDAS Civil. For model-3, the concrete flanges and folded steel webs are simulated by C3D8R solid elements and S4R shell elements, respectively. The concrete flanges and steel webs are merged using Boolean operations to make the mesh nodes follow the same deformation under loading. In the elastic stage, the constitutive relation for the concrete and steel follow a linear elastic constitutive relation. Both concrete and steel are considered to be homogeneous materials in the finite element model. The parameters of each model are shown in Table 1:

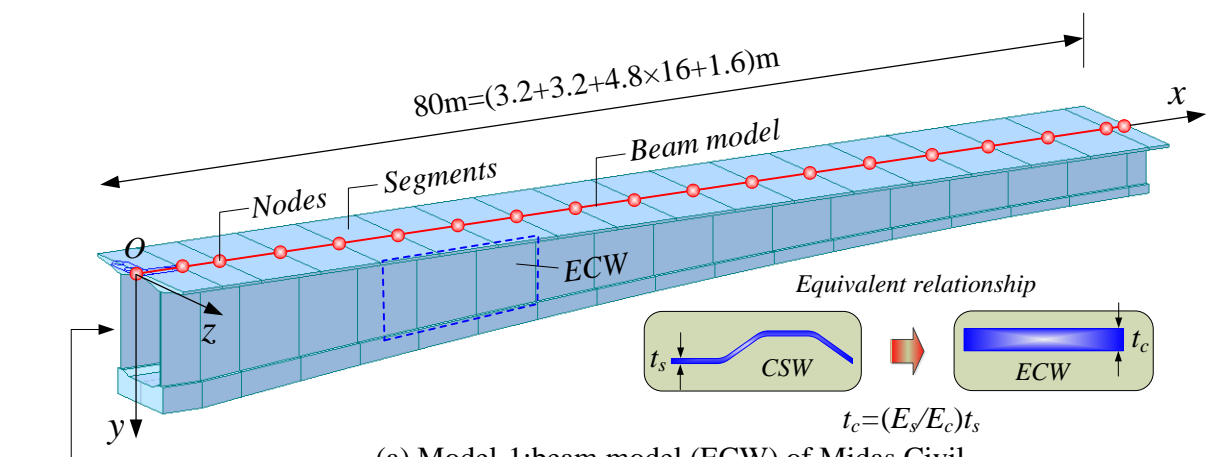

(a) Model-1:beam model (ECW) of Midas Civil

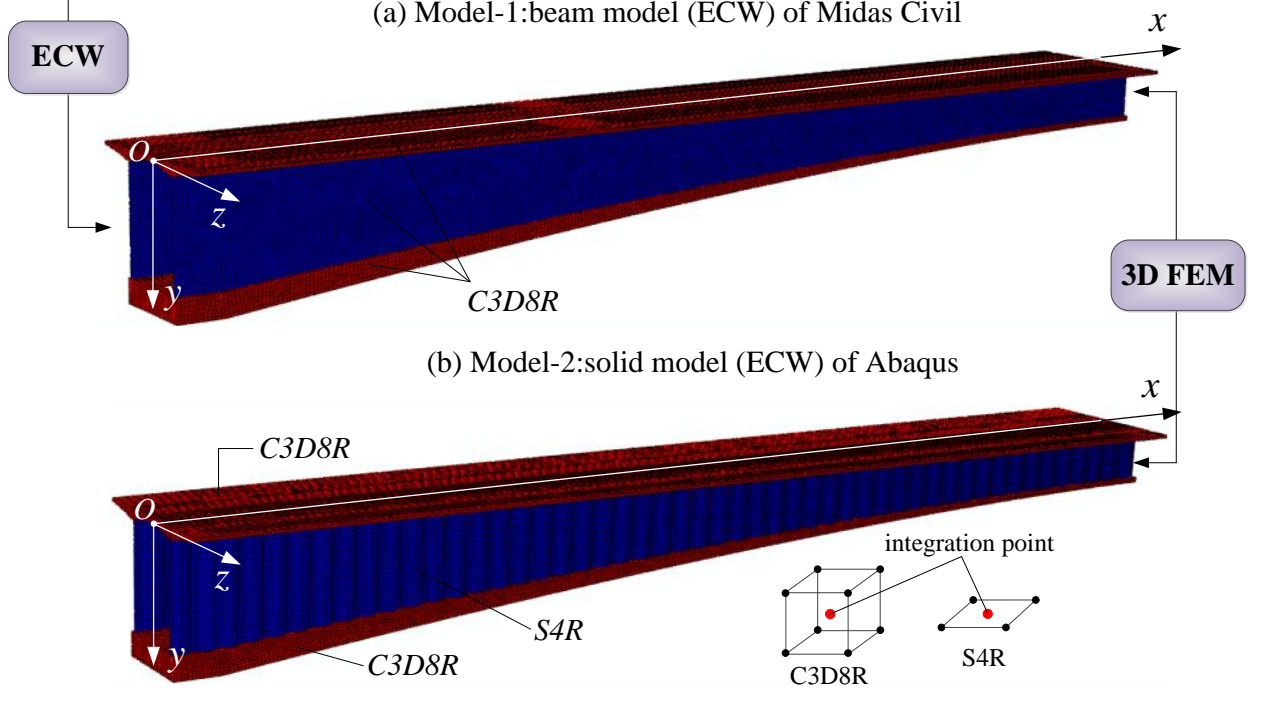

(c) Model-3: solid-shell model (CSW) of Abaqus

Fig. 2. Finite element models of MIDAS Civil and ABAQUS

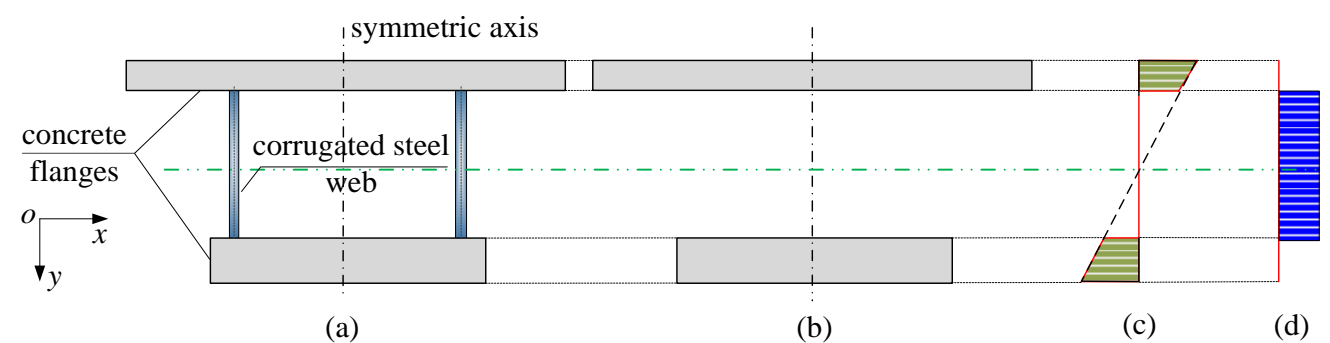

Fig. 3. Beam model of box girder with CSWs in MIDAS Civil (a) cross section; (b) the equivalent cross section; (c) the distribution of the normal stress; (d) the distribution of the shear stress

Table 1 Model parameter information for the cantilever beam

\begin{tabular}{c|c|c|c|c|c}
\hline Models & Software & Element type & Density $\left(\mathrm{kg} / \mathrm{m}^{3}\right)$ & Modulus of & Poisson's ratio \\
\hline
\end{tabular}




\begin{tabular}{|c|c|c|c|c|c|c|c|}
\hline & & & & & & Elasticity $\left(\mathrm{N} / \mathrm{m}^{2}\right)$ & \\
\hline \multirow{2}{*}{$\begin{array}{l}\text { Model-1 } \\
\text { (MIDAS) }\end{array}$} & \multirow{2}{*}{ MIDAS } & \multirow{2}{*}{\multicolumn{2}{|c|}{ Beam }} & Concrete & 2500 & $3.45 \times 10^{10}$ & 0.2 \\
\hline & & & & Steel & 7698 & $2.06 \times 10^{11}$ & 0.3 \\
\hline \multirow{2}{*}{$\begin{array}{l}\text { Model-2 } \\
\text { (ECW) }\end{array}$} & \multirow{2}{*}{ ABAQUS } & $C_{9}$ & C2D०D & Flanges & 2500 & $215 \div 010$ & 00 \\
\hline & & - viluta & CJDON & Web & 2500 & & 0.2 \\
\hline \multirow{2}{*}{$\begin{array}{l}\text { Model-3 } \\
\text { (CSW) }\end{array}$} & \multirow{2}{*}{ ABAQUS } & Concrete & C3D8R & Concrete & 2500 & $3.45 \times 10^{10}$ & 0.2 \\
\hline & & Steel & S4R & Steel & 7698 & $2.06 \times 10^{11}$ & 0.3 \\
\hline
\end{tabular}

\subsubsection{The loading conditions and contrast analysis results}

Following the construction process, two types of load conditions are discussed: gravity and the concentrated load (simulation of the hanging basket, $500 \mathrm{kN}$ ). Taking model-3 (CSW in Fig. 4) of ABAQUS as the standard model, this part attempts to realistically appraise the applicability of the MIDAS model. The contrastive research was conducted based on four aspects: the stress of the webs, the load sharing ratio of the webs, the total deflection, and the shear deformation and its proportion of the total deformation. The comparison results of each calculated section obtained by MIDAS and ABAQUS are as follows.

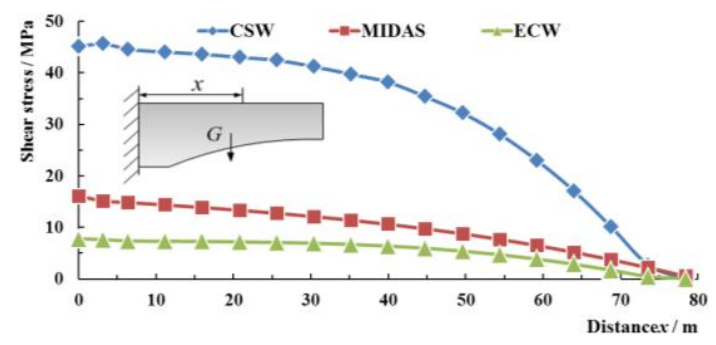

(a) Under the action of gravity

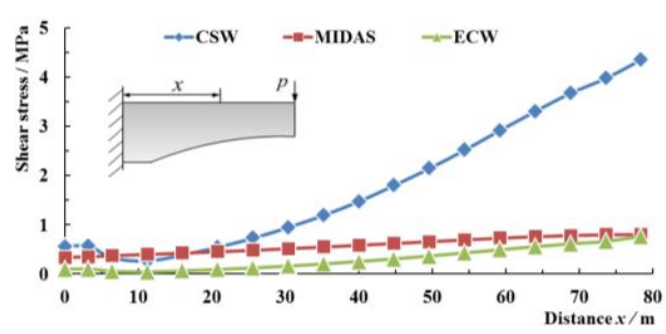

(b) Under the action of the concentrated load

Fig. 4. Mean shear stress in the steel webs along the longitudinal direction
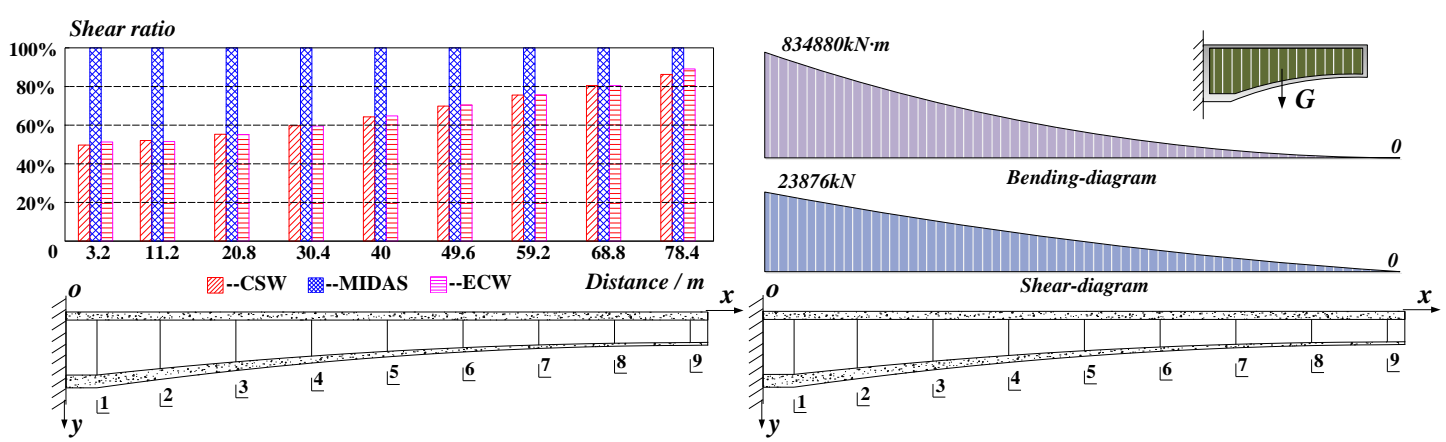

(a) Under the action of gravity
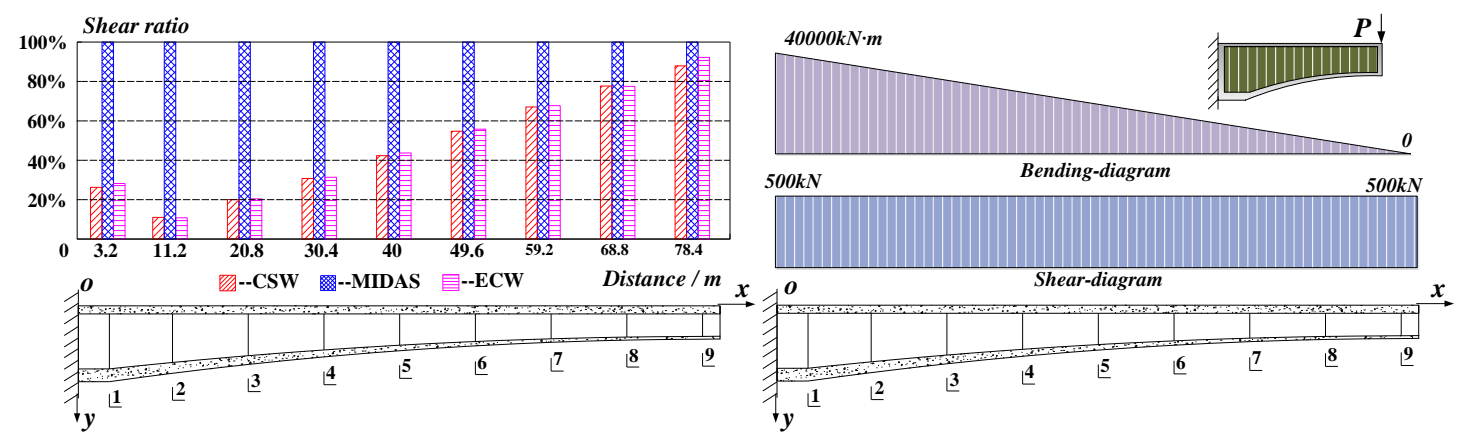
Fig. 5. Shear sharing ratio of the webs in each calculation section

From the perspective of shear stress in the webs and the proportion of the total load in the section, it is unreasonable that the folded steel webs were assumed to carry all shearing force of the non-prismatic box girder with CSWs. From Fig. 4, the shear stress in ECWs in the MIDAS model is nearly one-sixth of the stress in CSWs calculated using the CSW model in ABAQUS. The proposed reason for this is that the ECWs are nearly six times thicker than the CSWs converted based on the elastic moduli of the steel and concrete. On further analysis, the shear stress calculated using the MIDAS beam model is greater than that of the ECW model established in ABAQUS (the CSWs are all equivalent to the concrete webs in these models), and this result can be illustrated in Fig. 5. The ECWs in MIDAS are assumed to bear all vertical shear force whether the cantilever beam is under the action of gravity or the concentrated load. However, in the results of the 3D models (CSW and ECW models of ABAQUS) do not demonstrate this: the loading ratio of the webs varies in the longitudinal direction. For the CSW model in Fig. 5, the portion of the shear carried by the webs in the total shear ranges from $90 \%$ at the free end to $52 \%$ at the fixed end under gravity and from $92.6 \%$ to $10 \%$ under the concentrated load. The numerical calculations show that the results obtained from two ABAQUS models (CSW and ECW models) agree very well. Therefore, it is incorrect that the ECWs bear all shear in MIDAS Civil.

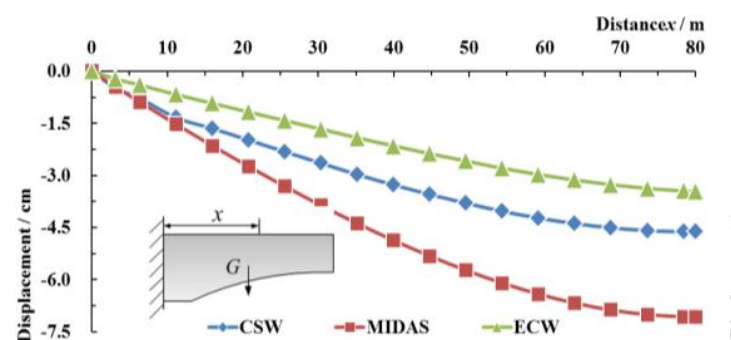

(a) Shear deformation under gravity

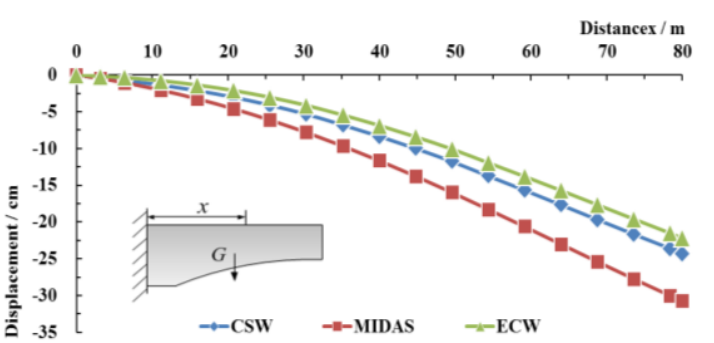

(b) Total deformation under gravity

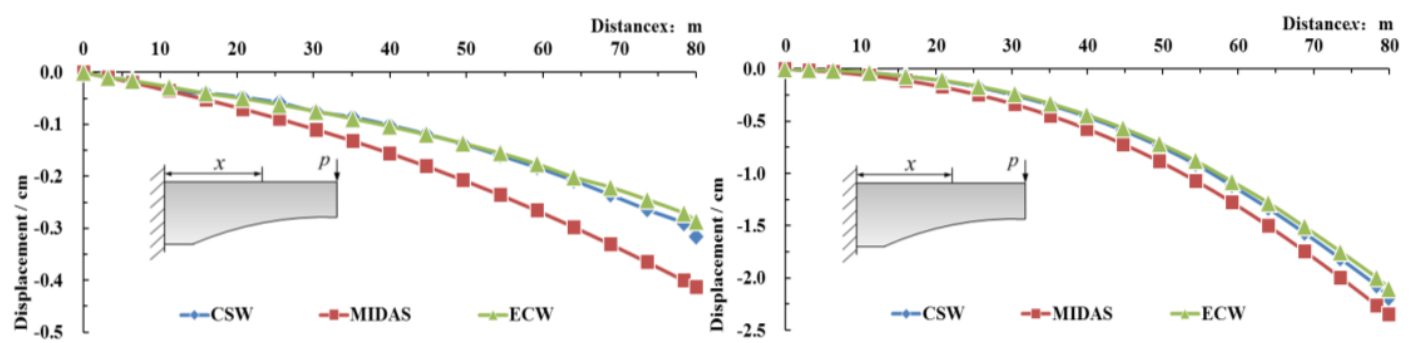

(c) Shear deformation under the concentrated load (d) Total deformation under the concentrated load

Fig. 6. Deformation of the cantilever beam with variable cross section

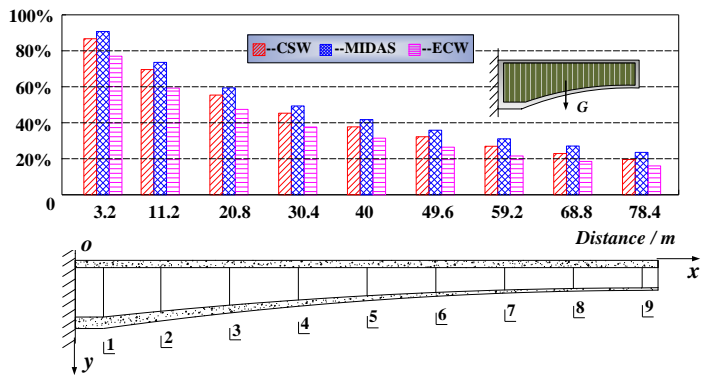

(a) Under gravity

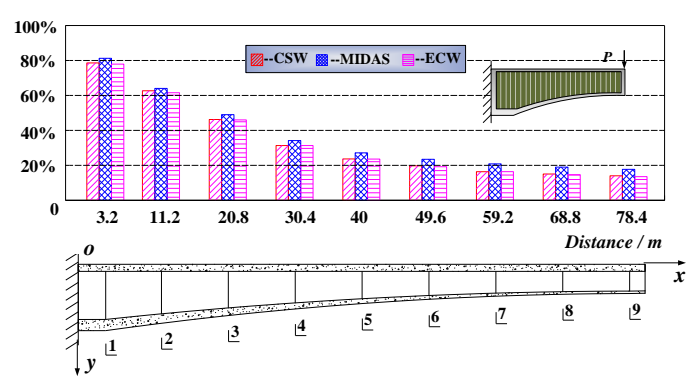

(b) Under the concentrated load

Fig. 7. The ratio of shear deformation to total deformation 
Fig. 6 and 7 show the numerical results of the shear deformation, total deformation and ratio between them under gravity and the concentrated load. According to the computational results, the shear deformation of the MIDAS model is larger than that of the ECW model in ABAQUS, although the CSWs are all equivalent to the flat concrete webs in these two models. This is because the shearing force in the webs is the main cause of shear deformation. In addition, the webs are assume to bear all vertical shear in the MIDAS beam model, whereas the shear is shared by the concrete flanges and the ECWs in the ABAQUS solid model. Apparently, the concrete flanges exhibit greater shear stiffness than do the ECWs; thus, the shear deformation calculated by MIDAS is relatively larger. More specifically, the calculated shear deformation caused by self-weight in MIDAS Civil is approximately 52.7\% larger than the accurate values at the free end and $30.5 \%$ larger than the accurate values under the concentrated load. In addition, the calculated values of the total deformation are also larger: the total deformation obtained from MIDAS Civil is approximately $26.4 \%$ greater than the actual deformation under gravity and $7.1 \%$ greater under the concentrated load. The primary reason for the computation error of the total deformation is that the replacement of the CSW with the ECW greatly increased its deadweight (the weight of the web may increase by $75.8 \%$ ). Fig. 7 shows that shear deformation cannot be ignored in the deflection calculation of the cantilever beams with CSWs. Shear deformation accounted for more than $20 \%$ of the total deformation in this structure. In contrast to conventional box girders, the thin folded steel webs weaken the shear rigidity of box girders with CSWs; therefore, the obvious shear deformation among web members must be included.

\subsection{Comparative analysis of the different equivalent models}

\subsubsection{Proposition and validation of the AOP model}

Based on the contrast analysis above, the calculation results obtained by MIDAS Civil cannot accurately reflect the mechanical behavior of the non-prismatic box girder with CSWs. The model will produce considerable errors if the folded steel webs are equivalent to the flat concrete webs. Specifically, the calculated values of shear stress are smaller than the actual values, and the calculated deformation is larger than the actual deformation. Therefore, it is necessary to search for a more precise and effective model to simulate CSWs. Moreover, the essential characteristic of CSWs is its accordion effect: the folded webs improve the buckling capacity of the steel webs at the expense of the decreased axis stiffness. Considering the unequal stiffness of CSWs in two orthogonal directions and that the cross-section distortion of the constrained CSWs is very small under shear flow for the edges of the CSWs embedded in the concrete flanges, steel webs with many corrugations can be equivalent to AOPs with different stiffness in perpendicular directions.

\subsubsection{Equivalent parameters of AOP model}

Although they are composed of an isotropic material, corrugated steel sheets exhibit an essentially non-isotropic behavior at the macro level due to the accordion effect of corrugations. Therefore, there were larger differences in the apparent elasticity modulus in the two principal directions. Differences also exist among the apparent Poisson's ratios. Additionally, the effective shear modulus should be reduced when the steel plate folds into the corrugated sheet. Therefore, the validity of the AOP model depends on the selection of the key parameters, namely, equivalent Young's modulus $E_{x x}$ and $E_{y y}$, equivalent Poisson's ratio $\mu_{x y}$ and $\mu_{y x}$, and equivalent shear module $G_{x y}$.

1) Effective elastic modulus in the longitudinal direction 
As shown in Fig. 8, a corrugated steel web with width equal to one corrugation pitch $\left(2 a_{1}+2 a_{2}\right)$, corrugation length $L$, and thickness $t$ is considered. The developed width of the corrugation is labelled as $2 a_{1}+2 a_{3}$, and the dimensions are shown in Fig. 8.

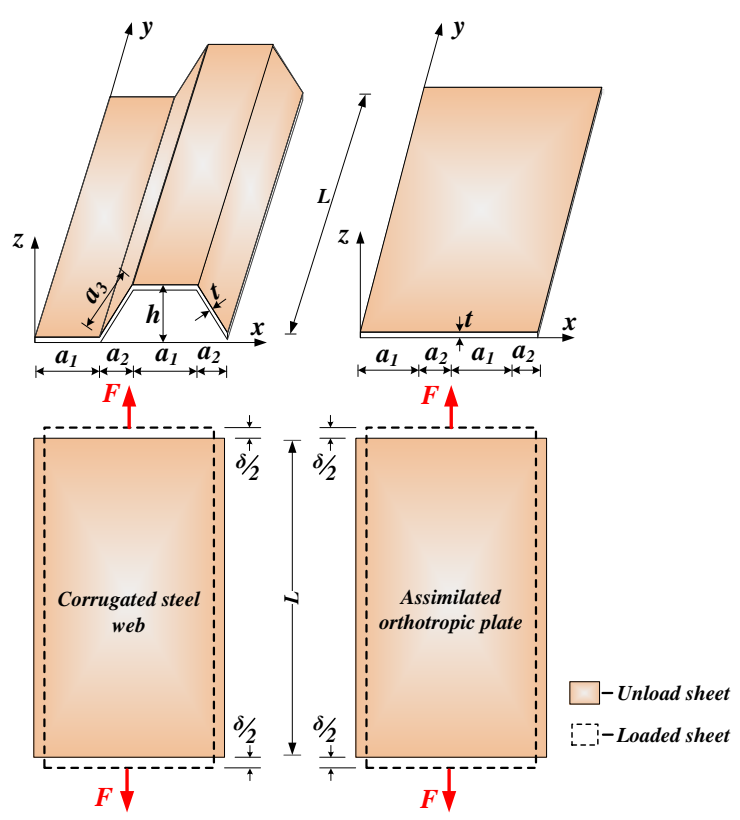

Fig. 8. Idealization of the CSWs

The effective elastic modulus $E_{y y}$ of the AOP can be obtained by the fact that both sheets must experience the same longitudinal deformation under an equal applied force $F$. Therefore, equating the two displacements,

$$
\frac{F L}{E_{0} 2\left(a_{1}+a_{3}\right) t}=\frac{F L}{E_{y y} 2\left(a_{1}+a_{2}\right) t}
$$

The following expression for $E_{y y}$ is obtained:

$$
E_{y y}=\frac{a_{1}+a_{3}}{a_{1}+a_{2}} E_{0}
$$

Where $E_{0}$ denotes the elasticity modulus of steel.

2) Effective elastic modulus in the transverse direction

The CSWs will undergo large axial deformation under the action of axial force. The apparent modulus of elasticity in the transverse direction is very low, so the effective elastic modulus $E_{x x}$ can be used instead. The bending moment diagram of the CSW under the axial force $F$ ( $F$ is now applied parallel to the transverse direction) is shown in Fig. 9. A corrugated sheet with a distance corresponding to half a wavelength between two adjacent zero bending moments was selected as the analytical unit, as shown in Fig. 9. 


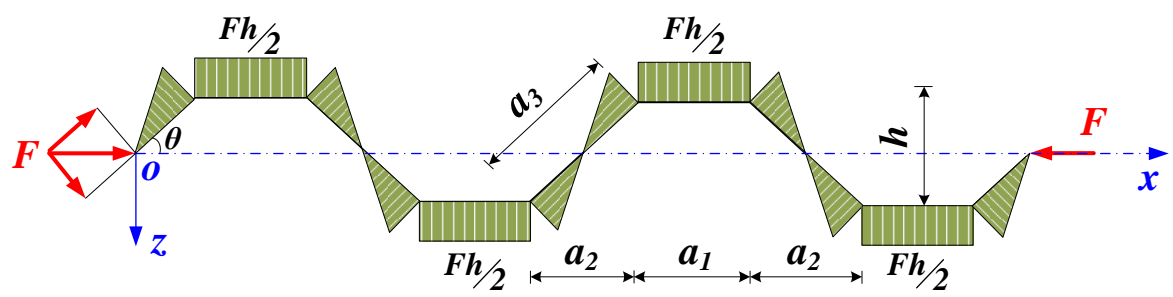

(a) The bending moment diagram of CSW under the axial force $F$

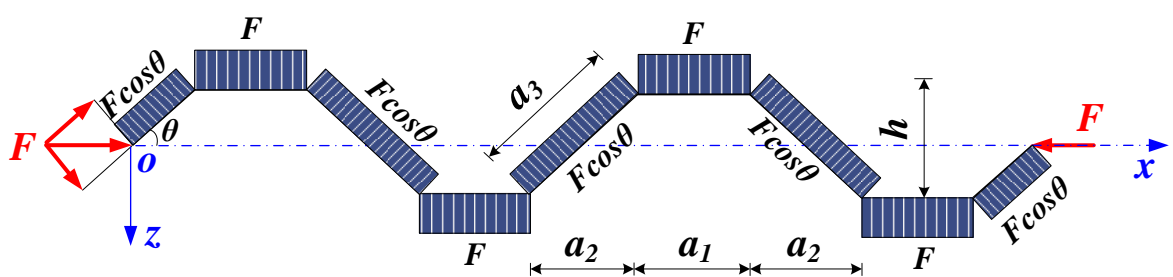

(b) The axial force diagram of CSW under the axial force $F$

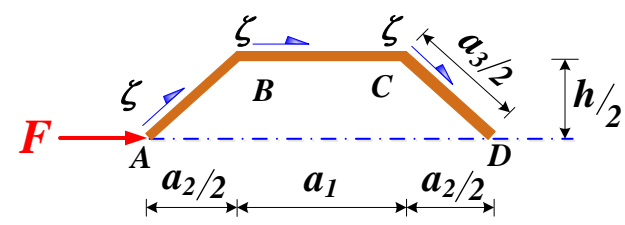

(c) The analytical unit of CSW

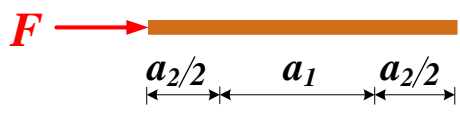

(d) The analytical unit of $A O P$

Fig. 9. The bending moment diagram and analytical unit of the CSW under the transverse load

According to Castigliano's Second Theorem, the derivation of the effective elastic modulus in the transverse direction $E_{x x}$ is as follows.

For convenience, the ordinate origin of the local coordinate system $\zeta$ is defined as the starting point (A, B and C) of each line, as shown in Fig. 9c.

For line $A-B$, when $0 \leq \zeta \leq a_{3} / 2$, the bending moment and axial force are: $M_{(\zeta)}=F \cdot \sin \theta \cdot \zeta, N_{(\zeta)}=F \cdot \cos \theta ;$ then $\frac{\partial M_{(\zeta)}}{\partial F}=\sin \theta \cdot \zeta, \frac{\partial N_{(\zeta)}}{\partial F}=\cos \theta ;$ For line $B-C$, when $0 \leq \zeta \leq a_{1}$, the bending moment and axial force are: $M_{(\zeta)}=F \cdot \frac{h}{2}, N_{(\zeta)}=F$; then $\frac{\partial M_{(\zeta)}}{\partial F}=\frac{h}{2}, \frac{\partial N_{(\zeta)}}{\partial F}=1$; For line $C$ - $D$, when $0 \leq \zeta \leq a_{3} / 2$, the bending moment and axial force are: $M_{(\zeta)}=F \cdot\left(\frac{h}{2}-\sin \theta \cdot \zeta\right), N_{(\zeta)}=F \cdot \cos \theta ;$ then $\frac{\partial M_{(\zeta)}}{\partial F}=\frac{h}{2}-\sin \theta \cdot \zeta, \frac{\partial N_{(\zeta)}}{\partial F}=\cos \theta$, in which $\sin \theta=\frac{h}{a_{3}}, \cos \theta=\frac{a_{2}}{a_{3}}$.

The deformation of the CSW analytical unit in the transverse direction $F$ is as follow:

$$
\begin{aligned}
\delta_{1} & =\int_{l} \frac{M_{(\zeta)}}{E_{0} I} \cdot \frac{\partial M_{(\zeta)}}{\partial F} d \zeta+\int_{l} \frac{N_{(\zeta)}}{E_{0} A} \cdot \frac{\partial N_{(\zeta)}}{\partial F} d \zeta \\
& =\frac{F h^{2}}{12 E_{0} I}\left(3 a_{1}+a_{3}\right)+\frac{F}{E_{0} A}\left(\frac{2 a_{2}^{2}}{a_{3}}+a_{1}\right)
\end{aligned}
$$

The deformation of the AOP analytical unit in the transverse direction $F$ is as follow: 


$$
\delta_{2}=\frac{F\left(a_{1}+a_{2}\right)}{E_{x x} A}
$$

252

Assuming that the thickness of the corrugated unit is $t$ and the longitudinal length is $l$; then $A=l t$.

$$
I=\frac{1}{12} l t^{3} \text {, and setting } \delta_{1}=\delta_{2} \text {, and the analytic expression for } E_{x x} \text { can be obtained as }
$$
follows:

$$
E_{x x}=\lambda\left(\frac{t}{h}\right)^{2} E_{0}
$$

Where, $\lambda=\frac{a_{1}+a_{2}}{3 a_{1}+a_{3}+\left(a_{1}+\frac{2 a_{2}^{2}}{a_{3}}\right)\left(\frac{t}{h}\right)^{2}}$

According to the above formula, the effective modulus in the transverse direction will be quite small due to the accordion effect of the corrugated sheet. To obtain quantitative knowledge, the comparison results of the transverse effective modulus of the three most common types of corrugated webs (CSW-1000, CSW-1200 and CSW-1600) in China are shown in Table 2

Table 2 The effective modulus $E_{x x}$ of three different forms of CSW ( $\left.h=1\right)$

\begin{tabular}{c|c}
\hline Type & The effective modulus $E_{x x}$ \\
\hline$C S W-1000$ & $0.0000401284 E_{0}$ \\
$C S W-1200$ & $0.0000453857 E_{0}$ \\
$C S W-1600$ & $0.0000465116 E_{0}$ \\
\hline
\end{tabular}

3) Principal Poisson's ratio $\mu_{y x}$

$\mu_{y x}$ is defined as the absolute value of the ratio between the transverse contraction strain and the longitudinal extension strain in the direction of the stretching force; therefore,

$$
\mu_{y x}=\left|\frac{\varepsilon_{x}}{\varepsilon_{y}}\right|
$$

Because the transverse strain $\varepsilon_{x}$ of the folded steel web is related only to the in-plane projection of the deformation, it should be equal to the transverse strain that would result in an orthotropic flat sheet. Thus, if a longitudinal strain $\varepsilon_{y}$ is imposed on both sheets, the identity expression for the transverse strains of the sheets will be [23]:

$$
\mu_{y x} \varepsilon_{y}=\mu_{0} \varepsilon_{y}
$$

By which

$$
\mu_{y x}=\mu_{0}
$$

4) Secondary Poisson's ratio $\mu_{x y}$

The secondary Poisson's ratio can be defined as

$$
\mu_{x y}=\left|\frac{\varepsilon_{y}}{\varepsilon_{x}}\right|
$$

Note that the expressions on the right-hand sides of Eq.(6) and Eq.(9) are not numerical 
reciprocals owing to the different definitions of the variables involved. $\mu_{x y}$ can be easily obtained from the Maxwell-Betti Law of Reciprocity [23]:

$$
E_{y y} \mu_{x y}=E_{x x} \mu_{y x}
$$

By which

$$
\mu_{x y}=\frac{E_{x x}}{E_{y y}} \mu_{y x}
$$

5) Effective shear modulus

In contrast to conventional box girders, the shear deformation of box girders with CSWs cannot be ignored. The shear modulus will be reduced after the flat plate folds into the corrugated sheet. British scholar [19] proposed a calculation method for the shear modulus of CSWs based on experiments and finite element analysis:

$$
G_{x y}=\frac{a_{1}+a_{2}}{a_{1}+a_{3}} G_{0}
$$

Where $G_{0}$ denotes the shear modulus of steel.

\subsubsection{Verification of AOP model by FEM}

Three numerical simulations were established to demonstrate the validity of the AOP model and the rationality of the above parameters. All of these finite element models were established in ABAQUS based on the dimensions of the Ningbo River bridge at the largest cantilever status (see Fig. 1). The difference between these models is the type of web used, namely, CSWs (CSW model) in the actual bridge; AOPs (AOP model), which must be validated below; and ECWs (ECW model) used in MIDAS Civil, as shown in Fig. 10. The thickness in the $Z$ direction of the thin orthotropic plate is far smaller than the dimensions in the $X$ and $Y$ directions; therefore, the normal stress $\sigma_{z z}$ and shear stres $\tau_{x z}, \tau_{y z}$ can be considered to be zero for the orthogonal steel plate under the action of vertical shear flow. Thus, the AOP was regarded as lamina in the plane stress condition. The elastic material parameters of the lamina defined in ABAQUS are shown in Fig. 10b. The load cases and other information about these FE models are consistent with the previous FE models (in Fig. 2). 


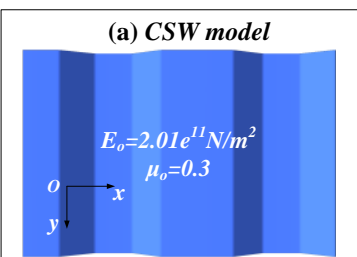

(b) AOP model

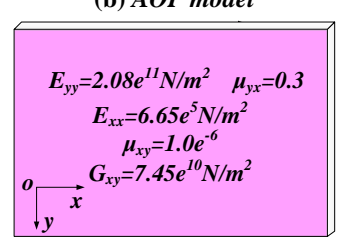

(c) ECW model

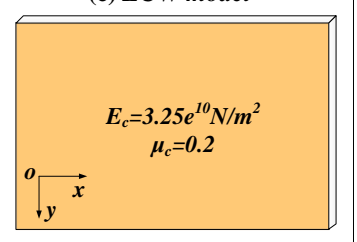

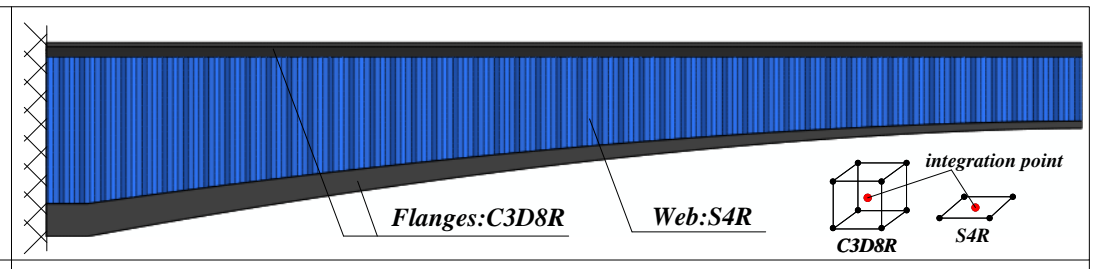
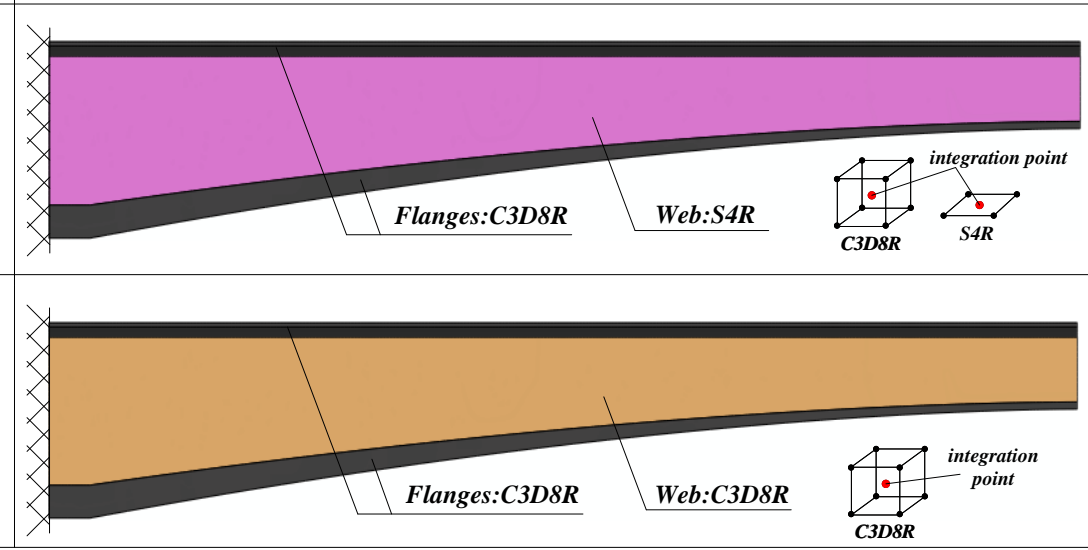

Fig. 10. The elastic material parameters of each equivalent calculation model

Comparison results and discussion

The calculation results for the shear stress and load sharing ratio of the webs in each FE model under gravity and the concentrated load are shown in Fig. 11 and 12.

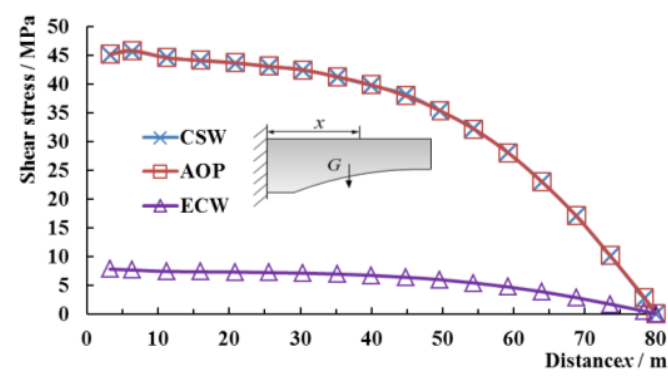

(a) Under gravity

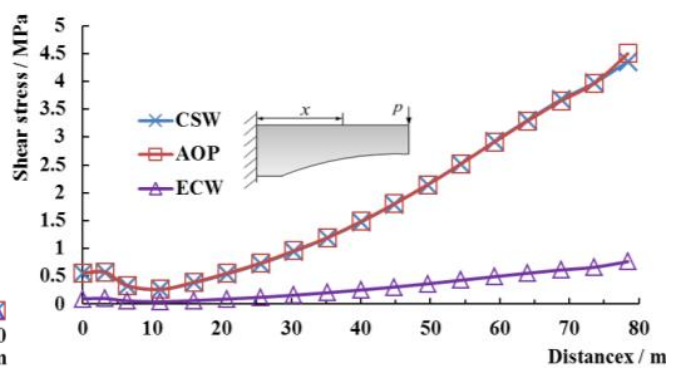

(b) Under the concentrated load

Fig. 11. Mean shear stress in the equivalent webs of each FE model
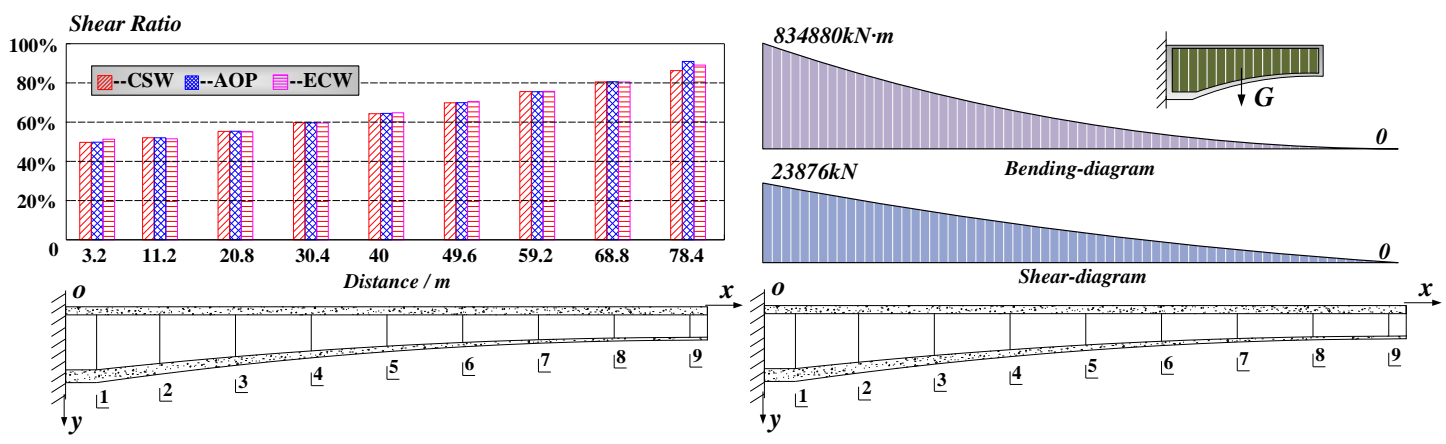

(a) Under gravity 

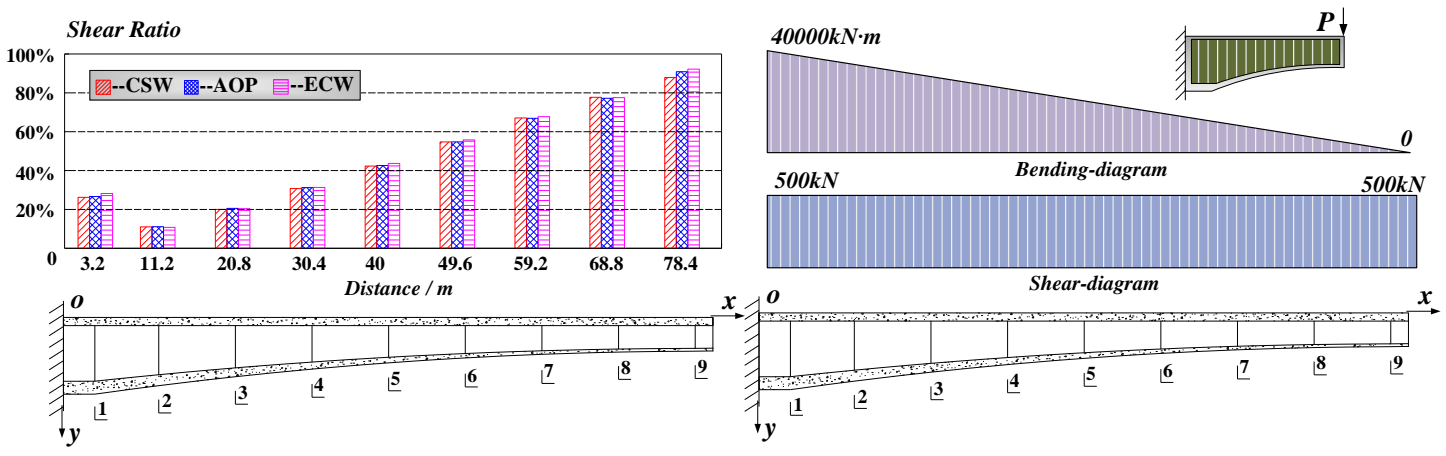

(b) Under the concentrated load

Fig. 12. Shear sharing ratio of the webs in each calculation section

Fig. 11 shows that the shear stress in the webs calculated using the AOP model and CSW model are almost the same in each calculating section regardless of the action of gravity or the concentrated force. However, the shear stress in the webs of the ECW model is approximately one-sixth of that of the former models. The shear-bearing proportions in the webs of these three types of FE models are generally the same: the shear will appear in the inclined bottom flange of the cantilever beam under hogging moment (the vertical component of the compressive stress under bending). In addition, the shear borne by the bottom flange evidently increases with increasing hogging moment; therefore, the shear in the webs is significantly reduced. The numerical results also demonstrate that it is unreasonable for the webs bearing the full vertical shear force is not reasonable for the non-prismatic box girder with CSWs. Through cross-comparative analysis of the shear stress and shear-bearing ratio in the webs of the three FE models, the AOP model can be used to substitute the CSW model for analysis and calculation.

Fig. 13 and 14 show the numerical calculation results obtained from each FE model for the 331 shear deformation and total deformation as well as the proportional relationship between them.

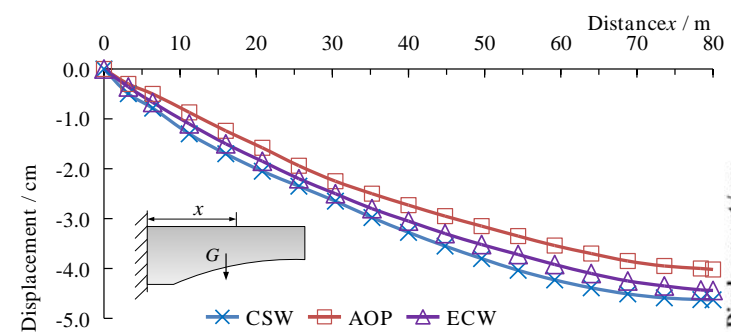

(a) Shear deformation under gravity

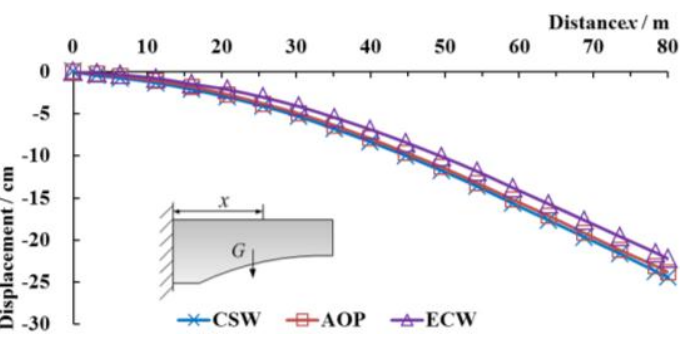

(b) Total deformation under gravity

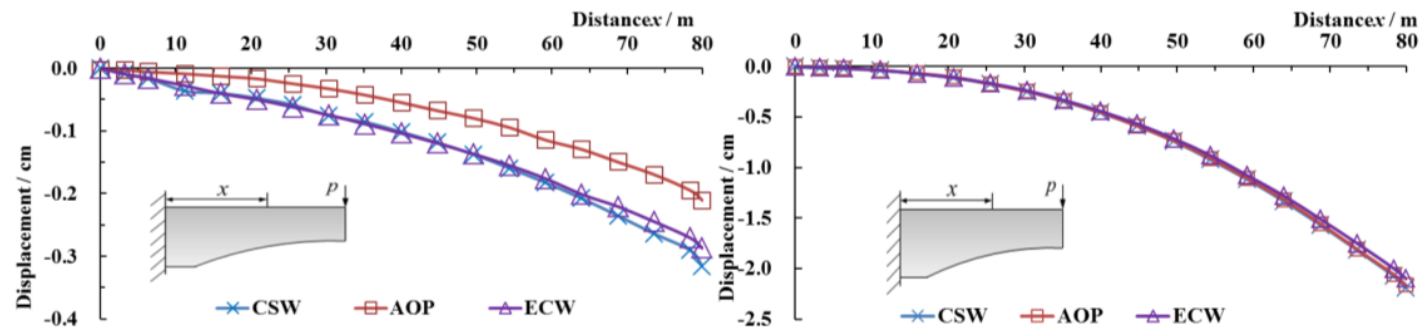

(c) Shear deformation under the concentrated load (d) Total deformation under the concentrated load

Fig. 13. Deformation of the cantilever beam in each FE model 


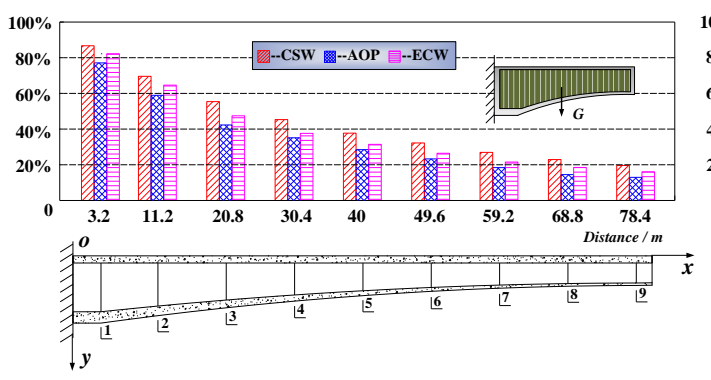

(a) Under gravity

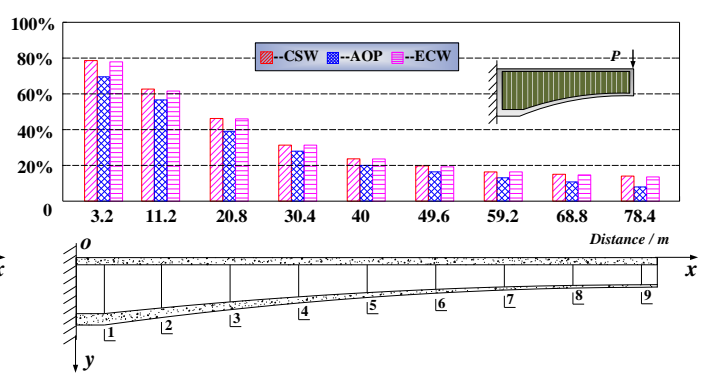

(b) Under the concentrated load

Fig. 14. The ratio of shear deformation to total deformation of each FE model

As shown in Fig. 13a and 13c, the numerical results demonstrate that the equivalent shearing stiffness of the AOP model is slightly higher than that of the CSW model. The calculated results using the AOP model are in good agreement with those obtained using the calibration models of CSWs and ECWs, which show that the calculation formula for the shear modulus in Eq. (12) is valid. In addition, the total deformations calculated using the AOP model are very close to those using the CSW and ECW models, as shown in Fig. 13b and 13d. The simulation results show that the relative errors for the total deformation were less than $5 \%$. These results demonstrate that the AOP model is effective and reliable and thus applicable to the calculation of the realistic deflections.

From the foregoing discussion, the comparison of the shear stress and deformation among three contrasting analysis models indicates that the AOP model can accurately reflect the structural characteristics of CSWs and can be used to improve the MIDAS Civil.

\section{Validation of the shear stress formula and the bridge experiment}

\subsection{Calculation of shear stress in non-prismatic box girders with CSWs}

The foregoing numerical analysis studied the mechanical properties of the non-uniform composite box girder with CSWs at the elastic stage. The finite element analysis indicated that it would be conservative to calculate the shear stress in a non-uniform girder with CSWs by ignoring the carrying capacity of the concrete flanges; the assumption that the webs bear all vertical shear force in the section is overly conservative for the design. In MIDAS Civil, CSWs are equivalent to thickening concrete webs. It would be unreasonable for the total shear in a section would be considered as resisted by the ECWs and to ignore the share of the inclined bottom flange. Many scholars have given greater consideration to the research on I- or box girders with uniform depth. The values and distributions of shear stress were usually oriented toward qualitative analysis via experiment or finite element methods. Due to the effect of the variable cross-section, the calculation formulas and distribution laws of shear stress in a non-uniform beams are quite different from those of uniform beams. In the previous paper [24], the general formula for shear stresses in a non-uniform box girder with CSWs was derived under static equilibrium and using the equivalent law of shearing stress of an infinitesimal segment. From this study, it was found that the additional shearing stress caused by the bending moment and the axial force should be considered in the non-prismatic box girder with CSWs. The formula is as follows (detailed explanations of the symbols in Eq. (13) can be found in reference [24]:

$$
\tau=\frac{Q S_{a}}{I b}+\frac{N}{b}\left(\frac{S_{a} \tan \alpha}{I}+\frac{1}{A} \frac{d A_{a}}{d x}-\frac{A_{a}}{A^{2}}\right)+\frac{M}{I b}\left(\frac{d S_{a}}{d x}-\frac{S_{a}}{I} \frac{d I}{d x}\right)
$$




\subsection{Introduction of the bridge experiment}

The shearing stress formula for the box girder with CSWs was developed and verified using the FE model. To further verify the correctness and accuracy of the theoretical formula, the authors conducted an experiment on a real bridge during the construction phase. The dimensions of the Fenghua River bridge with CSWs are described in detail (see Fig. 1).

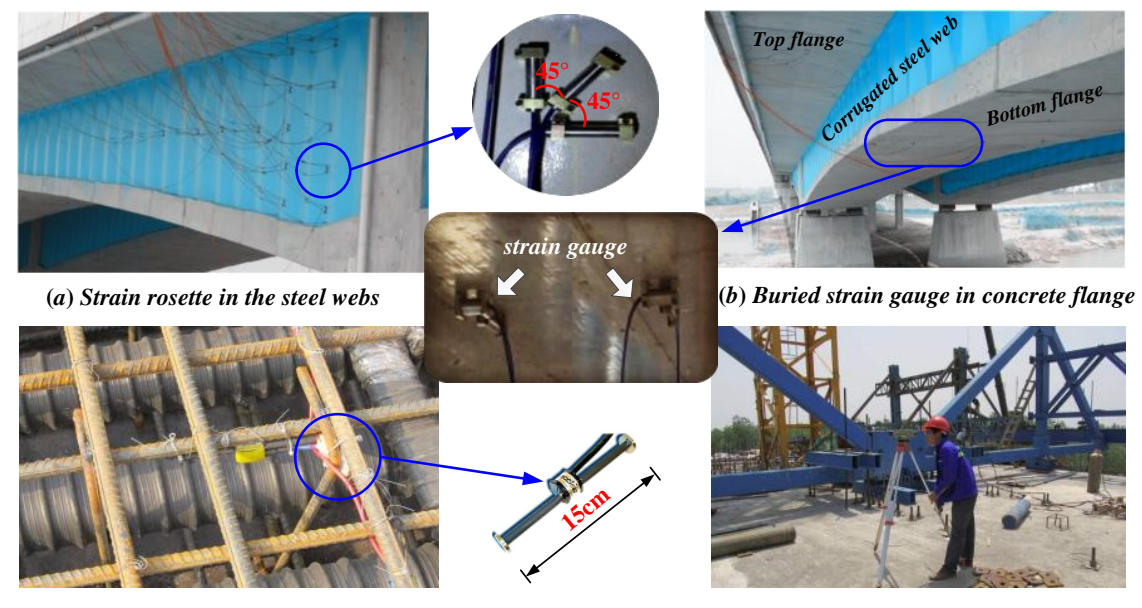

(c) Strain gauge of the longitudinal bar

(d) Observation of deformation with a level

Fig. 15. Experiment at Fenghua River bridge at Ningbo, China

The strain gauges (length: $15 \mathrm{~cm}$, type: HXT4-XB-160) were produced by ZHONGXI YUANDA Science and Technology Co., Ltd. (Beijing, China). The strain rosette consisted of the three strain gauges, where the angle between each strain gauge was 45 degrees, as shown in Fig. 15a. The strain rosettes were plastered in the CSWs of each calculation section (18 calculation sections along the longitudinal direction were selected; see Fig. 16) of the bridge. The buried strain gauge was fixed to the vertical reinforcements to measure the internal strain of the concrete flange. The strains were automatically collected by a computer data acquisition system (TDS-530, EARTH PRODUCTS CHINA Co., LTD.) via a strain gauge attached to the bar or the corrugated steel sheets. A high-precision electronic level (Type: DS30, YIGUANG SUZHOU Instrument Co., LTD.) was used to measure the deflection of the calculation sections under different conditions. In the static experiments, the strains of the CSWs and the concrete flanges and displacements of the calculation sections under different loads were collected. The cantilever construction process and the arrangement of strain gauge sensors are shown in Fig. 16. 
(a)

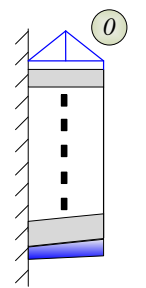

Construction of the segment No.0 and the arrangement of strain gauge sensors

(b)

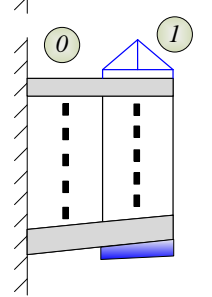

Construction of the segment No.1 and the arrangement of strain gauge sensors

(c)

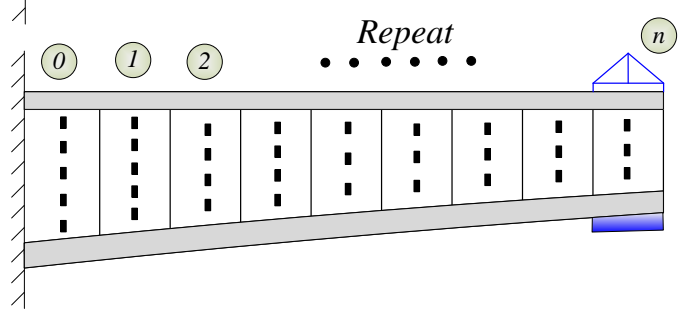

Construction of the segment No.n and the arrangement of strain gauge sensors

(d)

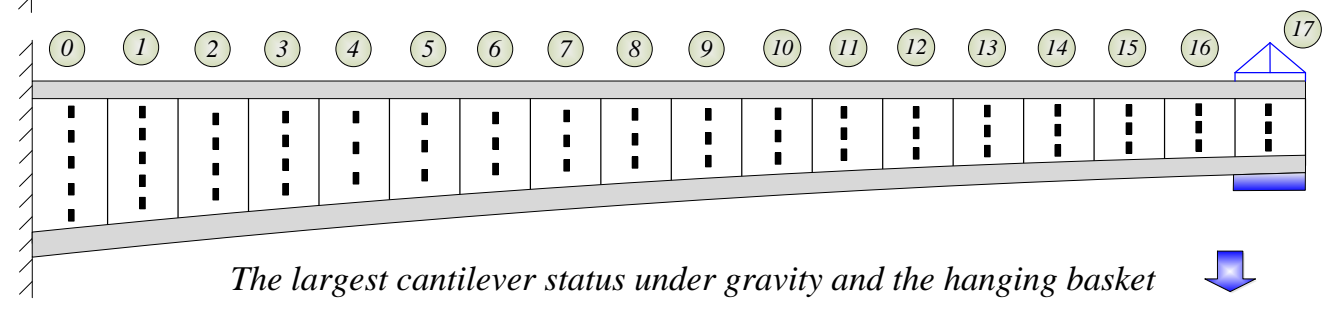

(e)

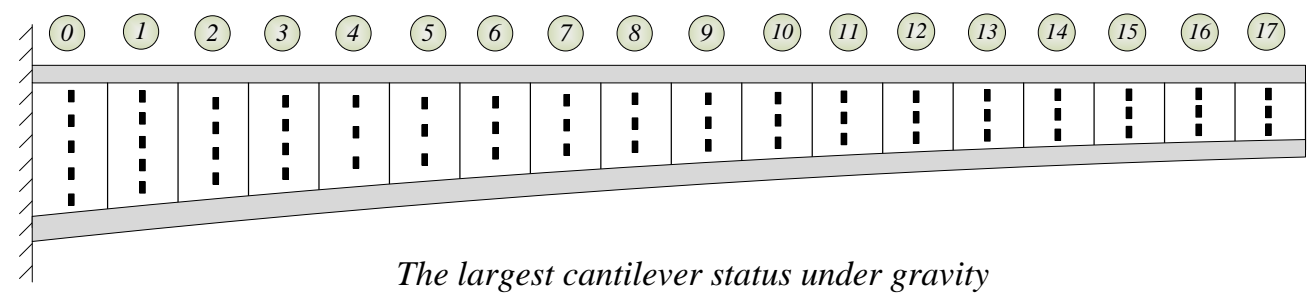

Fig. 16. Segmental cantilever construction and the arrangement of strain gauge sensors

As shown in Fig. 16a, engineers firstly constructed the segments No. 0 and then the strain gauge sensors were evenly spaced on the corrugated steel webs. The strain date were automatically collected by TDS-530. Noted that the initial reading of the strain sensors should be set to zero. Next, the hanging basket moved forward by the traction control system. Engineers constructed the segments No. 1 and stuck the strain gauge sensors like the first step, as shown in Fig. 16b. The process was then repeated with the progress of the construction as shown in Fig. 16c. Finally the bridge reached the longest cantilevered stage as shown in Fig. 16d. At this time, all the strain gauge sensors at each calculation section were attached to the segments. The experimental data represent the measured strain values of each calculation section under gravity and the concentrated force (the hanging basket). After that, the worker removed the hanging basket and collected data again, as shown in Fig. 16e. By this stage, the cantilever structure was only under its own weight.

\subsection{Comparison of the theoretical calculation and experimental data}

The theoretical results calculated using Eq. (13) and measured results from the bridge experiment under different load conditions are shown in Fig. 17. 


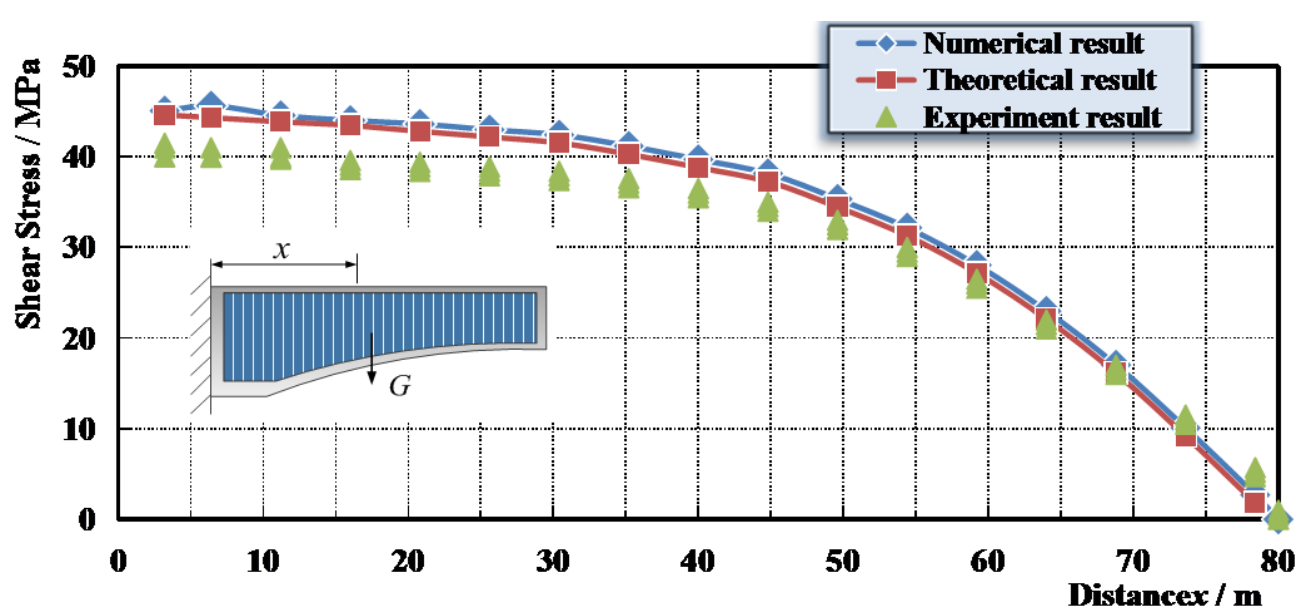

(a) Under gravity

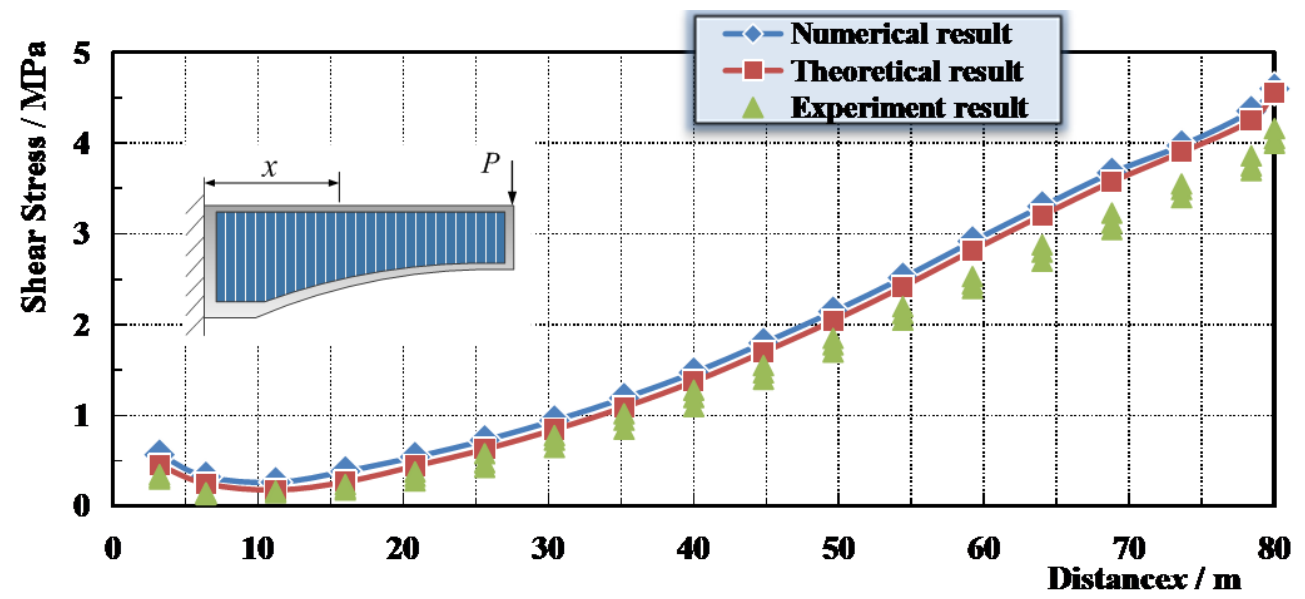

(b) Under the concentrated force

Fig. 17. Numerical, theoretical and experimental comparison results of shear stress in CSWs

In the comparison of the results in Fig. 17, the trends and values of shear stress calculated using the numerical and theoretical methods are in agreement with the experimental data, with the largest difference being less than 10\%. Thus, the efficiency and accuracy of the shear stress calculation formula has been verified via a practical engineering experiment for the first time.

Note that the shear stress first decreased but then increased from the fixed end to the free end in Fig. 17b, in which the cantilever beam is subjected to a vertical concentrated force $P$ at the free end. The apparent appearance, which shows the shear carrying capacity of the inclined concrete bottom flange, is very important. The experiments show that there is an apparent turning point in the shear stress-position curve: the corner point is located at the boundary of the flat bottom flange and the inclined flange. Obviously, the vertical component of the compressive stress in the inclined bottom flange caused by the hogging moment balanced the partial shear in the section. The research indicates that the mechanical behaviours of the non-prismatic and prismatic beam are quite different. However, the non-prismatic beam is more widely used in long-span bridges, and the analytical formula for the deflection of the non-prismatic box girder with CSWs represents another prominent problem to be solved. This will be discussed below.

\section{Derivation of the formula for bending deformation}

\subsection{Concept and calculation of equivalent inertia moment}

Compared with the beam with a constant cross section, bending problems concerning 
non-prismatic beams with CSWs are very complicated because the section flexural rigidity of the non-prismatic beam is variable lengthwise, and the formulas in the classical mechanics of materials for beams with uniform cross section are no longer valid. To make these formulas applicable to non-prismatic beams, the idea of the equivalent inertia moment of beams with variable cross sections is presented in this paper, therein providing the basis for a united calculation formula for the bending deformation of non-prismatic and prismatic beams.

The calculation method for the equivalent inertia moment will be demonstrated using a cantilever beam under the concentrated force and gravity.

1) Cantilever beam with point force at free end

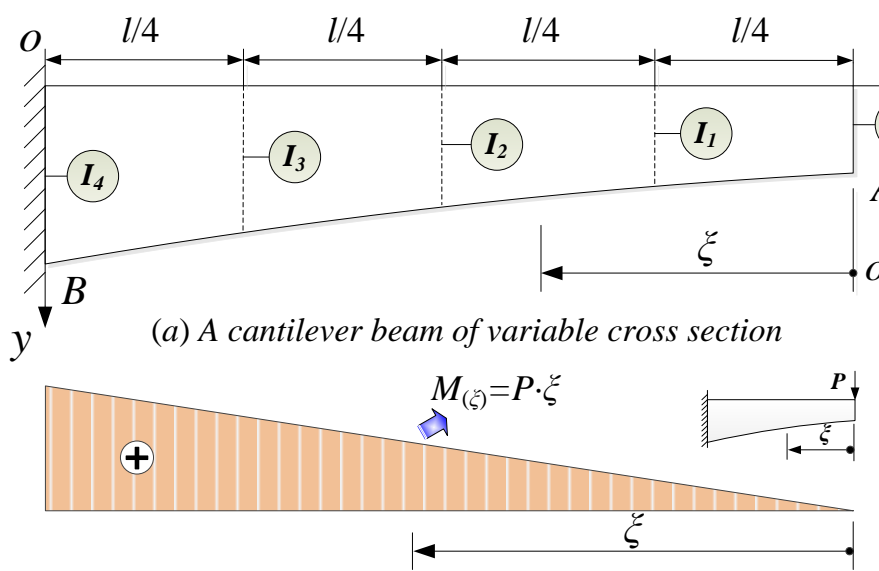

(b) Moment diagram under the concentrated force $P$

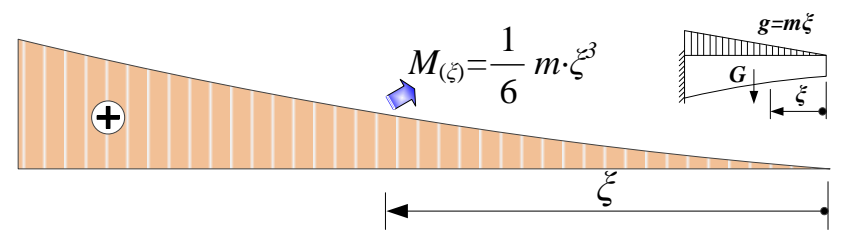

(c) Moment diagram under the gravity

Fig. 18. A cantilever beam with variable cross section and its bending diagram under load $\left(I_{j}\right.$, $j=0,1,2,3,4$. the inertia moment of the selected section)

A cantilever beam with a varying cross section is shown in Fig. 18a, where the fixed end and free end are located at section $B$ and section $A$. The beam was artificially divided into 4 equal segments. $I_{j}(j=0,1,2,3,4)$ represents the moment of inertia about a centroidal axis. According to the numerical integration using the Simpson formula,

$$
\int_{a}^{b} f(\xi) d x=\frac{b-a}{3 n}\left[y_{0}+4 \times\left(y_{1}+y_{3}+\cdots+y_{n-1}\right)+2 \times\left(y_{2}+y_{4}+\cdots+y_{n-2}\right)+y_{n}\right]
$$

in which $y_{i}=f\left(\xi_{i}\right), i=0,1,2 \ldots, n$ are the values of the integral function $f(\xi)$ when $\xi=\xi_{i}$, and $n$ is the interval number of the closed interval $[a, b]$, which must be even.

According to Castigliano's Second Theorem, the bending deformation of the cantilever beam under concentrated force $P$ can be written as follow:

$$
\delta_{1}=\int_{o}^{l} \frac{P \xi^{2}}{E I(\xi)} d \xi
$$

Using Eq. (14), letting $n=4, a=0, b=l, f(\xi)=\frac{P \xi^{2}}{E I(\xi)}$, Eq. (15) becomes 


$$
\begin{aligned}
\delta_{1} & =\int_{0}^{l} \frac{P \xi^{2}}{E I(\xi)} d \xi=\frac{P l}{12 E}\left\{0+4 \times\left[\frac{\left(\frac{l}{4}\right)^{2}}{I_{1}}+\frac{\left(\frac{3 l}{4}\right)^{2}}{I_{3}}\right]+2 \times \frac{\left(\frac{l}{2}\right)^{2}}{I_{2}}+\frac{l^{2}}{I_{4}}\right\} \\
& =\frac{P l^{3}}{12 E}\left(\frac{1}{4 I_{1}}+\frac{1}{2 I_{2}}+\frac{9}{4 I_{3}}+\frac{1}{I_{4}}\right)
\end{aligned}
$$

Assuming that an equivalent beam with a constant cross section is used to replace the above non-prismatic beam, the equivalent inertia moment is denoted by $I_{e q}$, and the deformation is

$$
\delta_{e q}=\int_{o}^{l} \frac{P \xi^{2}}{E I_{e q}} d \xi=\frac{P l^{3}}{3 E I_{e q}}
$$

Based on the principle of equal deformation, set Eq. (16) equal to Eq. (17).

$$
\frac{P l^{3}}{12 E}\left(\frac{1}{4 I_{1}}+\frac{1}{2 I_{2}}+\frac{9}{4 I_{3}}+\frac{1}{I_{4}}\right)=\frac{P l^{3}}{3 E I_{e q}}
$$

Simplifying Eq. (18) above, $I_{e q}$ can be written as

$$
I_{e q}=\frac{16}{\frac{1}{I_{1}}+\frac{2}{I_{2}}+\frac{9}{I_{3}}+\frac{4}{I_{4}}}
$$

Note that when the beam has a constant cross-section $\left(I_{1}=I_{2}=I_{3}=I_{4}=I\right)$, it can be easily found from Eq. (19) that $I_{e q}=I$.

2) Cantilever beam under gravity

Similar to the derivation process above, the load form is regarded as a triangularly distributed load $g=m x,(m$ is a constant related to the material of the structure). The bending deformation of the cantilever beam under gravity can be written as follow:

$$
\delta_{2}=\int_{o}^{l} \frac{m \xi^{6}}{36 E I(\xi)} d \xi
$$

Using Eq. (14), and setting $n=4, a=0, b=l, f(\xi)=\frac{m \xi^{6}}{36 E I(\xi)}$, Eq. (20) becomes

$$
\delta_{2}=\int_{0}^{l} \frac{m \xi^{6}}{36 E I(\xi)} d \xi
$$

$$
=\frac{m l^{7}}{442368 E}\left(\frac{1}{I_{1}}+\frac{32}{I_{2}}+\frac{729}{I_{3}}+\frac{1024}{I_{4}}\right)
$$

Assuming that an equivalent beam with a constant cross section is used to replace the above non-prismatic beam, using the equivalent inertia moment is denoted by $I_{e q}$, and the deformation is 


$$
\delta_{e q}=\int_{o}^{l} \frac{m \xi^{6}}{36 E I_{e q}} d \xi=\frac{m l^{7}}{252 E I_{e q}}
$$

Based on the principle of equal deformation, set Eq. (21) equal to Eq. (22).

$$
\frac{m l^{7}}{442368 E}\left(\frac{1}{I_{1}}+\frac{32}{I_{2}}+\frac{729}{I_{3}}+\frac{1024}{I_{4}}\right)=\frac{m l^{7}}{252 E I_{e q}}
$$

Simplifying Eq. (23), $I_{e q}$ can be written as

$$
I_{e q}=\frac{12288}{7 \times\left(\frac{1}{I_{1}}+\frac{32}{I_{2}}+\frac{729}{I_{3}}+\frac{1024}{I_{4}}\right)}
$$

\subsection{Bending deformation of non-prismatic beam with its equivalent inertia moment}

Based on the equivalent inertia moment, the bending deformation of the non-prismatic beams with CSWs can be obtained using the classical prismatic beam theory of the mechanics of materials. For the calculation of bending deformation, the steel-concrete composite section is also simplified as the equivalent concrete section (Fig. 3b), namely, the bending stiffness of the thin CSWs is ignored in the calculation of the bending stiffness of each section. A cantilever beam is shown in Fig. 19, where the $X$-axis is positive to the right and the $Y$-axis is positive in the downward direction. The beam can have a positive curvature when the upper surface fibers are in tension; in contrast, a negative curvature is obtained when the upper surface fibers are in compression.ng

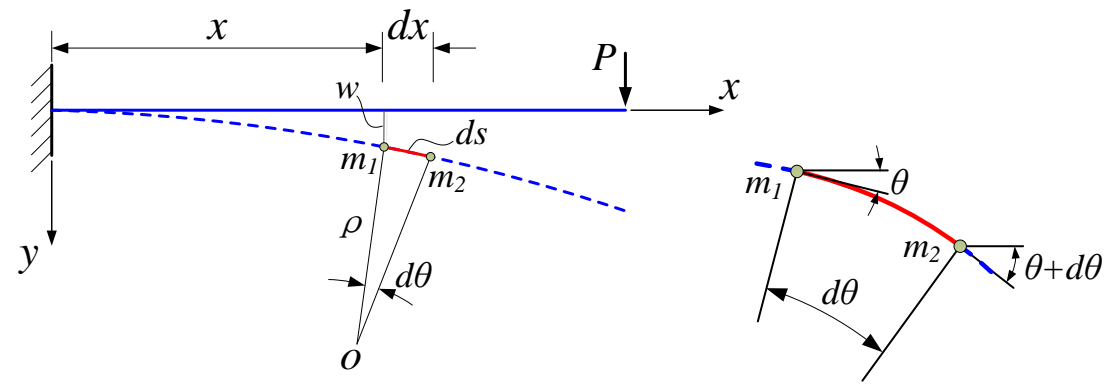

Fig. 19. Bending deformation curve of a cantilever beam

Based on the beam theory of mechanics of materials (Timoshenko, 1977), the relation between the curvature and bending moment is as follows:

$$
\kappa=\frac{1}{\rho}=-\frac{M}{E_{c} I_{c}}
$$

According to the geometrical relationship in Fig. 18,

$$
\kappa=\frac{1}{\rho}=\frac{d \theta}{d s}
$$

in which the curvature $\kappa$ is the rate of change of deflected angles $\theta$ with the flexural curve $s$. For the case in Fig. 19, curvature $\kappa$ is positive and gradually increases along the $x$ direction. In practice, the bending deflection of a real bridge is usually small. The deflection angles of the neutral axis $\theta$ and the slope of the curve are incredibly small; thus, the following can be assumed:

$$
d s=d x, \quad \theta \approx \tan \theta=\frac{d w_{b}}{d x}
$$


where $w_{b}$ is the bending deformation. Substituting Eq. (25) into Eq. (26) and solving using Eq. (27),

$$
\frac{d^{2} w}{d x^{2}}=-\frac{M}{E I}
$$

1) The bending deformation under the concentrated load

The relation for the load and deformation of the non-prismatic box girder with CSWs can be expressed as the following second-order differential equation:

$$
E_{c} I_{e q} w_{b}^{\prime \prime}=-M=P(l-x)
$$

Note that the bending stiffness of the box girder with CSWs mainly originates from the concrete flanges, and the bending stiffness of the CSWs is usually ignored [3]. In addition, the elasticity modulus $E_{c}$ and equivalent inertia moment $I_{e q}$ were calculated based on the concrete flanges.

Integrating Eq. (29) once gives

$$
E_{c} I_{e q} w_{b}^{\prime}=-\frac{P}{2}(l-x)^{2}+C_{1}
$$

The Integration constant $C_{l}$ can be obtained according to the boundary condition at the fixed end, namely, $w_{b}^{\prime}(0)=0$; thus, $C_{1}=\frac{P l^{2}}{2}$, and Eq.(30) becomes

$$
w_{b}^{\prime}=\frac{P}{E_{c} I_{e q}}\left(l x-\frac{x^{2}}{2}\right)
$$

Integrating Eq. (31) again,

$$
w_{b}=\frac{P}{E_{c} I_{e q}}\left(\frac{l}{2} x^{2}-\frac{x^{3}}{6}\right)+C_{2}
$$

Obviously, the integration constant $C_{2}=0$ is based on the boundary condition: $w_{b}(0)=0$.

Therefore, the bending deformation under the concentrated load should be

$$
w_{b}=\frac{P}{E_{c} I_{e q}}\left(\frac{l}{2} x^{2}-\frac{x^{3}}{6}\right)
$$

2) The bending deformation under gravity

The differential relation between the deformation and gravity of the cantilever beam is

$$
E_{c} I_{e q} w_{b}^{\prime \prime}=-M=\frac{1}{6} m(l-x)^{3}
$$

where $m$ is a constant related to the mass of the structure ( $m=\frac{2 M g}{l^{2}}$, where $M$ denotes the mass of the structure and $g$ denotes the gravitational acceleration).

Integrating Eq. (34) once gives

$$
E_{c} I_{e q} w_{b}^{\prime}=-\frac{m}{24}(l-x)^{4}+D_{1}
$$

The Integration constant $D_{l}$ can be obtained according to the boundary condition at the fixed end, 
namely, $w_{b}^{\prime}(0)=0$. Thus, $D_{1}=\frac{m l^{4}}{24}$, and Eq. (35) becomes

$$
E_{c} I_{e q} w_{b}^{\prime}=-\frac{m}{24}(l-x)^{4}+\frac{m l^{4}}{24}
$$

Integrating Eq. (36) again,

$$
E_{c} I_{e q} w_{b}=\frac{m}{120}(l-x)^{5}+\frac{m l^{4}}{24} x+D_{2}
$$

Obviously, the integration constant $D_{2}=-\frac{m l^{5}}{120}$ is based on the boundary condition: $w_{b}(0)=0$.

Therefore, the bending deformation under the concentrated load should be

$$
w_{b}=\frac{m}{E_{c} I_{e q}}\left[\frac{1}{120}(l-x)^{5}+\frac{l^{4}}{24} x-\frac{l^{5}}{120}\right]
$$

\section{Derivation of the formula for shear deformation}

\subsection{Computational assumption}

Because the shear stiffness of the thin corrugated sheet is smaller than that of the conventional concrete webs, the shear deformation cannot be ignored in the box girders with CSWs. The calculation of the shear deformation in the non-prismatic box girder with CSWs is rather complex for several reasons.

1) The cross-sectional shape and size of the non-prismatic box girder with CSWs vary along the length, and the solution method of direct integration is more complex.

2) It is not accurate to assume that the CSWs bear all vertical shear force in the non-prismatic beam. Note that the concrete flanges (especially the inclined bottom flange) bear a certain portion of the shear force.

3) The shear resistance property of the corrugated sheets cannot be fully applied due to the accordion effect, and the shear deformation will be larger when the flat steel plate folds into the corrugated sheets.

On the basis of elastic mechanics theory, this paper first presents a calculation method for determining the shear deformation in the non-prismatic box girder with CSWs by considering the factors of variable cross-sections, the shear bearing capacity of the concrete flanges and the accordion effect of the corrugated sheets. To make the derivation process more rigorous, the author will present the following hypotheses:

1) The structure completely works in the elastic state, and the materials obey Hooke's law.

2) The plane sections approximately remain quasi plane after deformation [25-26]. Namely, the normal stress in the concrete flanges distributes linearly

3) The connectors' slip is ignored at the interface between concrete flanges and steel webs.

4) The shear stress is evenly distributed over the web; the lengthwise strain of the folded web is near zero [24].

5) The additional shear stress in the inclined bottom flange caused by the bending moment is evenly distributed transversely, and the steel webs balance the additional shear stress individually [24]. 


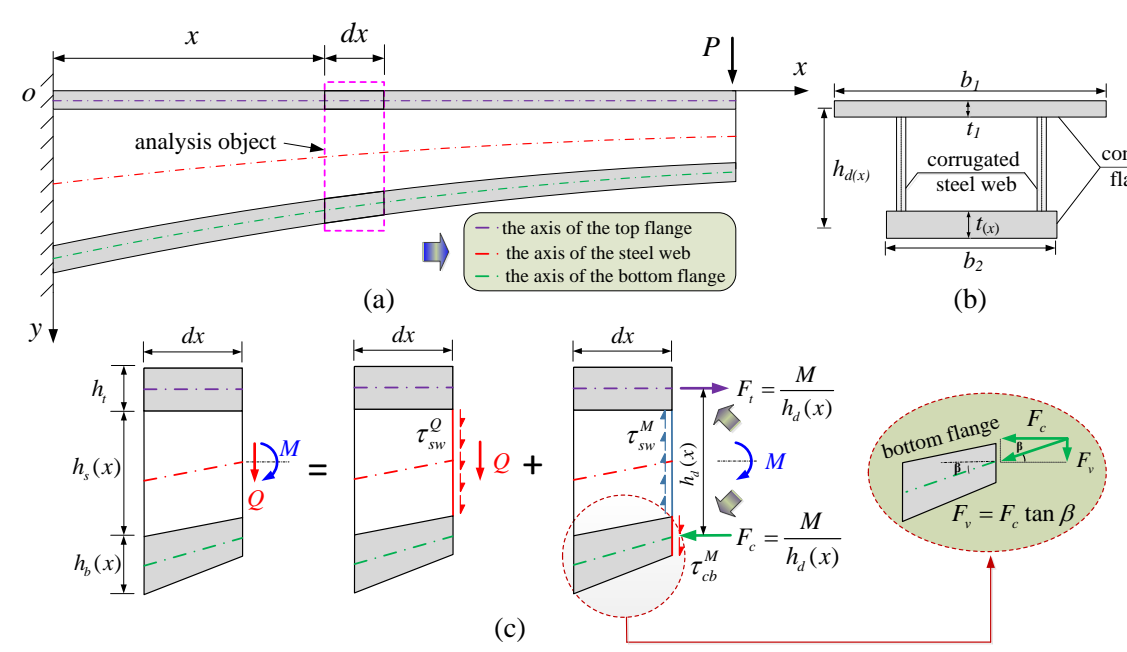

Fig. 20. The non-prismatic cantilever beam with CSWs and the stress state in the cross section

(a) elevation (b) cross section (c) shearing stress in the cross section of an infinitesimal segment Fig. 20c shows an infinitesimal segment of the box girder with CSWs loaded with combined shear and moment, and the actual shear stress can be considered as the independent superposition of these two parts. Specifically, the shear stress caused by the vertical shear [24] is assumed to be resisted by the folded webs under the shear force; CSWs cannot resist the axial force due to the accordion effect; therefore, the normal stress could be regarded as acting solely on the concrete flanges. Therefore, the bending moment is equivalent to a pair of parallel force systems $\left\{F_{t}, F_{c}\right\}$ that act on the neutral axis of the top and bottom flanges. Note that the horizontal force $F_{c}$ is the horizontal component of the resultant compression force acting on the bottom flange, and the vertical component of the resultant compression force $F_{v}$ can be obtained by the vector decomposition method $\left(F_{v}=F_{c} \tan \beta\right)$. This is because of $F_{v}$, which causes the additional shear stress and shear deformation in the concrete bottom flange. The authors have previously proven that the additional shear stress caused by the bending moment is self-balanced [24]. Hence, the vertical force component (equal and opposite to $F_{v}$ ) is shared by the CSWs, which causes the shear deformation of the CSWs. With these basic assumptions and concepts, this paper presented a theoretical model and practical formula for calculating the shear deformation of the non-prismatic box girders with CSWs.

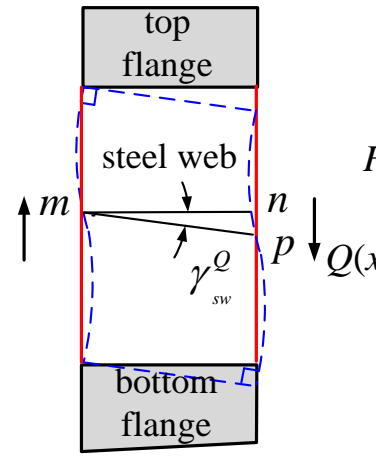

(a)

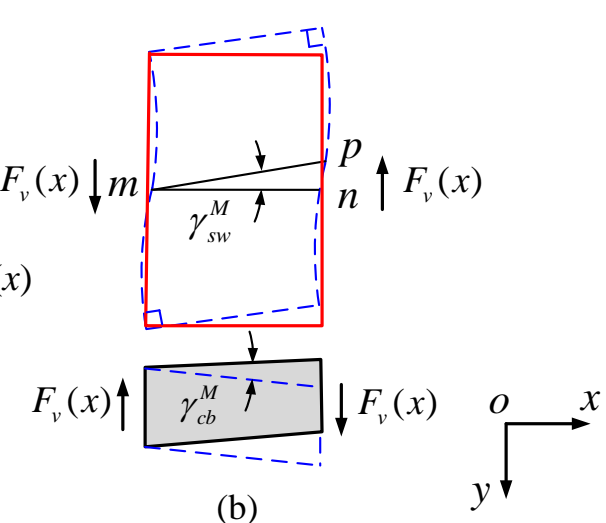

(b)

Fig. 21. Shear deformation in a non-prismatic beam (a) shear deformation by shear force (b) additional shear deformation by bending moment 
the effects of the shearing force and bending moment. The shear deformation is produced by the shear force, which, for a beam with CSWs, causes an element of the beam of length $d x$ to be deformed, as shown in Fig. 21a. In contrast to prismatic beams, an additional shear deformation produced by the bending moment causes the additional shear deformation of the corrugated webs and the concrete bottom flange in the opposite direction, as shown in Fig. 21b. The Line $m n$ represents the original axis of the beam, and line $m p$ denotes the position of this line after the shear deformation has occurred.

The slope of the deflection curve of the beam due to the shearing force is approximately equal to the shear strain at the neutral axis (see Fig. 21a). Thus, the authors denote the deflection due to the shear force and bending moment as $w_{s}$, which results from the shear deformation of the CSWs caused by the shearing force and the shear deformation of the CSWs and of the concrete bottom flange caused by the bending moment. The following expression for the slope is then obtained:

$$
\frac{d w_{s}}{d x}=\gamma_{s w}^{Q}(x)+\gamma_{c b}^{M}(x)-\gamma_{s w}^{M}(x)=\frac{\alpha_{s w} Q(x)}{G_{x y} A_{s w}(x)}+\frac{\alpha_{c b} F_{v}(x)}{G_{c} A_{c b}(x)}-\frac{\alpha_{s w} F_{v}(x)}{G_{x y} A_{s w}(x)}
$$

In which $\gamma_{s w}^{Q}, \gamma_{c b}^{M}$, and $\gamma_{s w}^{M}$ denote the shear strain at the neutral axis of the CSWs under shearing force, of the concrete bottom flange under bending moment, and of the CSWs under bending moment, respectively, and $\frac{Q(x)}{A_{s w}(x)}, \frac{F_{v}(x)}{A_{c b}(x)}$, and $\frac{F_{v}(x)}{A_{s w}(x)}$ are the average shear stresses obtained by dividing the shear force by the cross-sectional area of the CSWs, by dividing the vertical force resulting from the bending moment by the cross-sectional area of the concrete bottom flange, and by dividing the vertical force resulting from the bending moment by the cross-sectional area of the CSWs, respectively. $G_{x y}$ is the equivalent shear module of the CSWs considering the reduction in stiffness when the flat steel plate is folded into the corrugated sheet. $G_{c}$ is the shear modulus of concrete. $\alpha_{s w}$ and $\alpha_{c b}$ are the shear coefficients by which the average shear stress should be multiplied to obtain the shear stress at the centroid of the cross section. For the box girders with CSWs, the steel webs carry almost all the shear force, the shear stress is approximately uniform throughout the height of the webs. The additional shear stress caused by the bending presents the linear distribution along the concrete bottom flange [24]; thus, $\alpha_{s w}=\alpha_{c b}=1.0$

After the successive integration of Eq. (39), the shear deflection $w_{s}$ is

$$
w_{s}=\int \frac{\alpha_{s w} Q(x)}{G_{s e q} A_{s w}(x)} d x+\int\left[\frac{\alpha_{c b} F_{v}(x)}{G_{c} A_{c b}(x)}-\frac{\alpha_{s w} F_{v}(x)}{G_{s e q} A_{s w}(x)}\right] d x+E_{1}
$$

The constant $E_{l}$ can be solved through the boundary condition $\left(\left.w_{s}\right|_{x=0}=0\right)$. Note that the geometric layout of the concrete bottom flange is parabolic in practical engineering; and the thickness of the bottom flange often varies longitudinally. Therefore, the centroidal axis of the bottom flange is a curved line, and the equation of the curve can be expressed as a function $g(x)$ 
for a given bridge. Then the tangent value of the angle between the centroidal axes and the horizontal line (see Fig. 20) is then the slope of the curve equation at a certain point. The vertical component of the resultant compression force $F_{v}(x)$ becomes

$$
F_{v}(x)=F_{c} \tan \beta=\frac{M(x)}{h_{d}(x)} \tan \beta=\frac{M(x)}{h_{d}(x)} \frac{d g(x)}{d x}
$$

Because the cross-sectional area $\left(A_{s w}(x), A_{c b}(x)\right)$ of the steel webs and the concrete bottom flange in Eq. (40) change longitudinally in the non-prismatic box girders with CSWs, it is difficult to obtain a specific expression for the uncertainties of the interval variables. Therefore, the numerical integration of the shear deformation can be conducted in MATLAB.

Based on the principle of the superposition of displacements, in the Timoshenko beam, the section deformation is the sum of two contributions, namely, one is due to bending, and the other is the shear deformation, as follows:

$$
w=w_{b}+w_{s}
$$

\subsection{Conclusion and discussion}

The total deformation and shear deformation of the practical example are calculated using Eq. (42) and Eq. (40). A comparison of the theoretical and numerical results is shown below in Fig. 22a to Fig. 22d below.

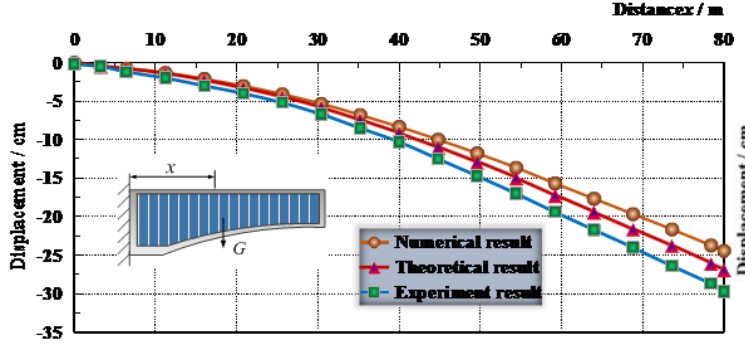

(a) Total deformation under gravity

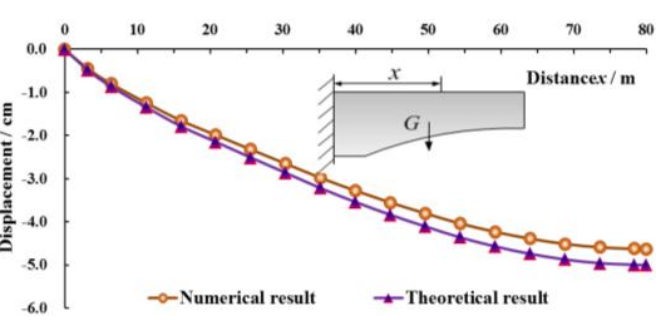

(b) Shear deformation under gravity

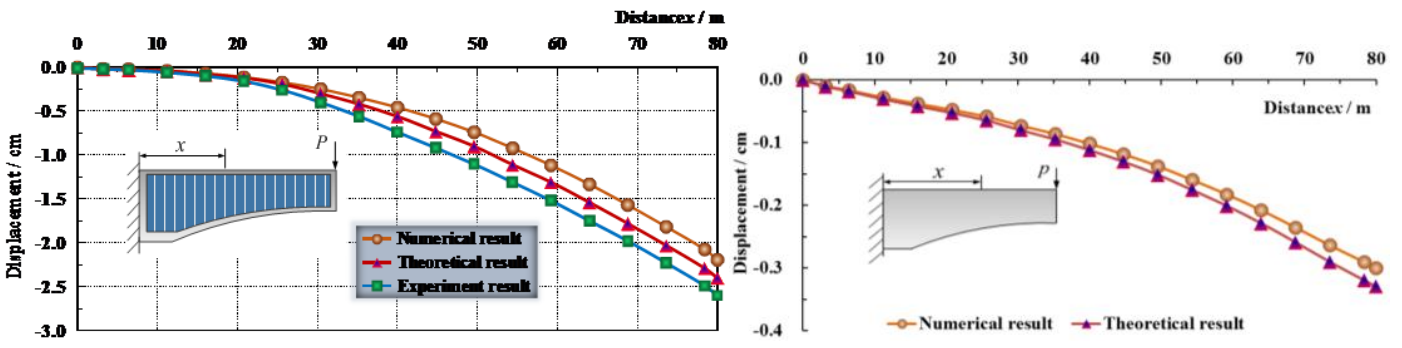

(c) Total deformation under the concentrated force (d) Shear deformation under the concentrated force

Fig. 22. The comparison of the displacement result from the theoretic and numerical results

Comparing the theoretical, numerical and experimental results above, the results of the FE simulation and the measured data are found to verify the validity of the theoretical analysis performed in this paper. The experimental results are the observations of the total deformation (the sum of the bending deformation and shear deformation) of the structure under different load conditions. More specifically, Fig. 22a and Fig. 22b show that the maximum error of the total deformation under gravity is less than $7.7 \%$, and the error in shear deformation is approximately 7.4\%. Fig. $22 \mathrm{c}$ and $22 \mathrm{~d}$ indicate that the maximum error in the total deformation under the 
concentrated force is less than $7.6 \%$, and the error in shear deformation is approximately $8.0 \%$. Therefore, the accuracy of the deflection formula is sufficiently high for practical purposes. In addition, this study also found that the shear deformation accounts for a significant proportion of the total deformation. The deflection value can increase by $20 \%$ at the free end under gravity when considering shear deformation. Note that the shearing force is not the sole cause of the shear deformation in the non-prismatic box girders with CSWs; the additional shear stress caused by the bending moment and the shear-resisting capacity of concrete flange can also cause shear deformation. To quantify the contribution of each factor to the shear deformation, the author decomposed the shear deformation of folded webs and the concrete flange subjected to combined moment and shear using Eq. (40), and the dominant factor causing the shear deformation is discussed as follows.

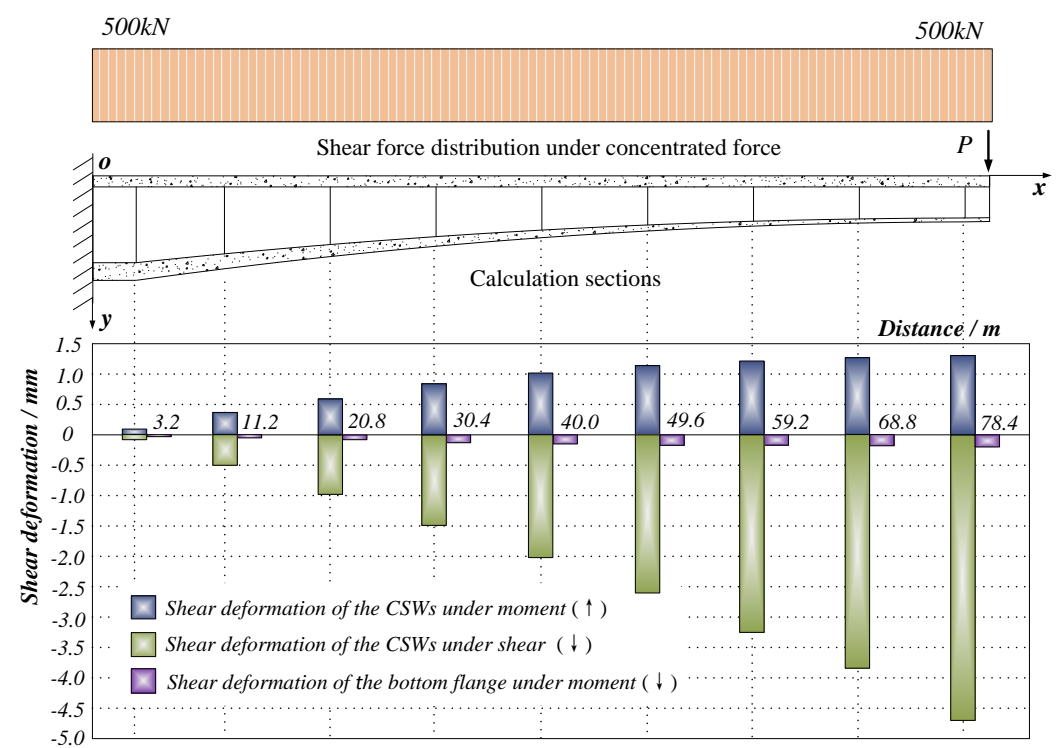

Fig. 23. Decomposition diagram of shear deformation under concentrated force

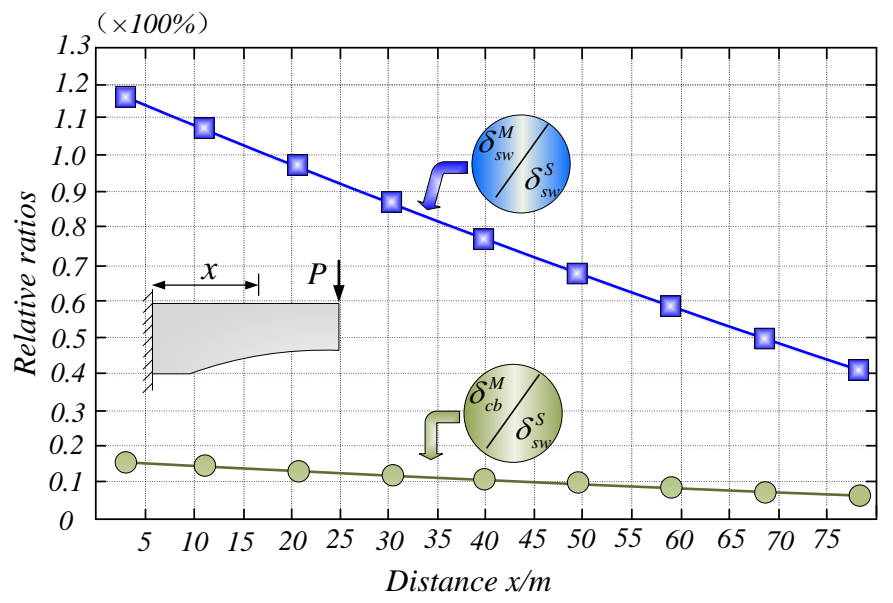

Fig. 24. The relative ratios of shear deformations caused by bending moment and shear force ( $\delta_{c b}^{M}$ denotes the shear deformation of the concrete bottom flange by moment; $\delta_{s w}^{M}$ denotes the shear deformation of the steel webs by moment; $\delta_{s w}^{S}$ denotes the shear deformation of the steel webs by shear) 
For a non-prismatic cantilever beam with CSWs subjected to a concentrated force (500 kN) at the free end, the shear deformation of the steel webs and concrete bottom flange under the action of bending moment and shear force is considered. From Fig. 23, the shear deformation of the concrete bottom flange caused by the additional shear stress is relatively small (the ratio of the shear deformation of the concrete flange under bending to the shear deformation of steel webs under shear ranges from $15.2 \%$ at the fixed end to $6.0 \%$ at the free end). In addition, the shear deformation of the steel web caused by the addition shear stress deriving from the bending moment is relatively large (the ratio of the shear deformation of the steel webs under bending to the shear deformation of steel webs under shear ranges from $115.2 \%$ at the fixed end to $40.4 \%$ at the free end). The shear deformations can offset each other due to opposing shear stress directions. The results indicate that the calculated value of the shear deformation will increase by $52.4 \%$ when not considering the action of the hogging moment; therefore, the shear deformation caused by the bending moment cannot be ignored in the calculations for the deflection.

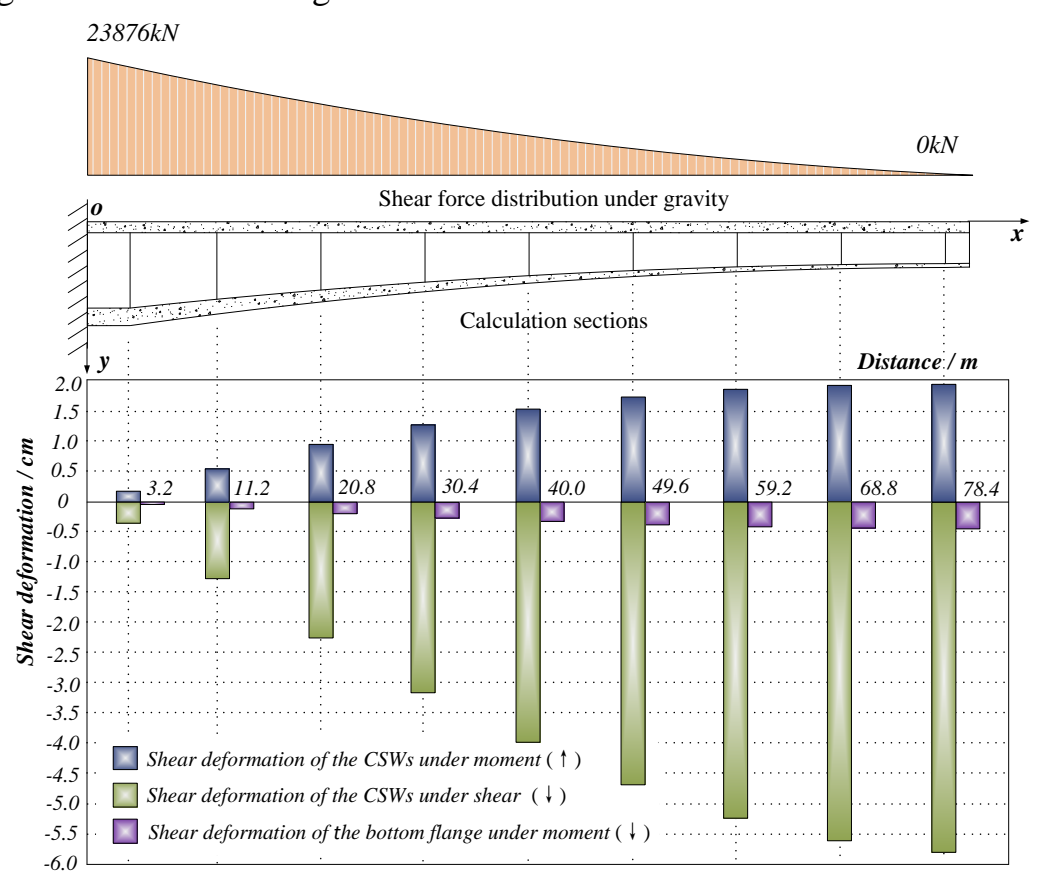

Fig. 25. Decomposition diagram of shear deformation under gravity

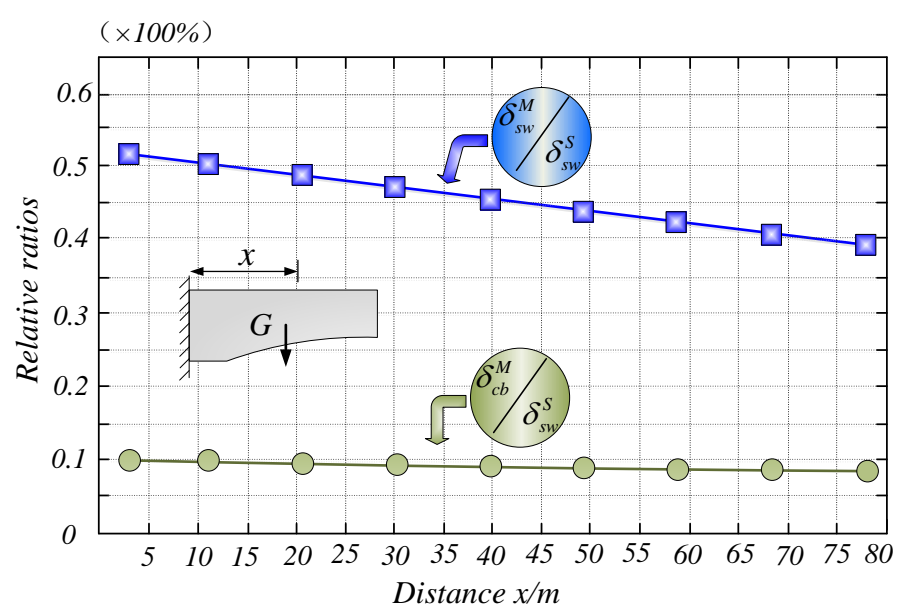

Fig. 26. The relative ratios of shear deformations caused by bending moment and shear force (the 
The shear deformation regularity of the bridge under gravity is similar to the situation above.

688 It is evident from Fig. 25 that both the shear deformation caused by the bending moment and the 689 shear gradually increase from the fixed end to the free end. Among them, the shear deformation of 690 the CSWs under shear continues to obtain the dominant proportion. Taking the shear deformation 691 of CSWs caused by the shear as the standard, the ratio of the shear deformation of the concrete 692 flange under bending to the shear deformation of the steel webs under shear ranges from $10.1 \%$ at 693 the fixed end to $8.7 \%$ at the free end. The ratio of the shear deformation of steel webs under 694 bending to the shear deformation of steel webs under shear ranges from $51.6 \%$ at the fixed end to $69539.2 \%$ at the free end. Accordingly, the shear deformation of the concrete bottom flange caused by 696 the additional shear stress driven by the bending moment is relatively small; however, the shear 697 deformation of the CSWs is relatively large and thus cannot be ignored in the calculation.

\section{6. Comparison of AOP and ECW model}

Based on the above research, a new model (the AOP model) for improving the analysis module of the box girders with CSWs in MIDAS Civil is presented. The exactness of the proposed model and the calculation of related parameters are verified by a series of computer-based models and a bridge experiment. In addition, this model is not simply an extension of the original program or an improvement of the algorithm; instead, the tremendous advances in computing theory and methodology, and the modelling efficiency of complex-shaped corrugated webs can also be improved. A comparison of the computational principles of the AOP and ECW models are as follows. 
AOP model

(assimilated orthotropic plate)

Proposed model

in this paper
ECW model

(flat equivalent concrete web)

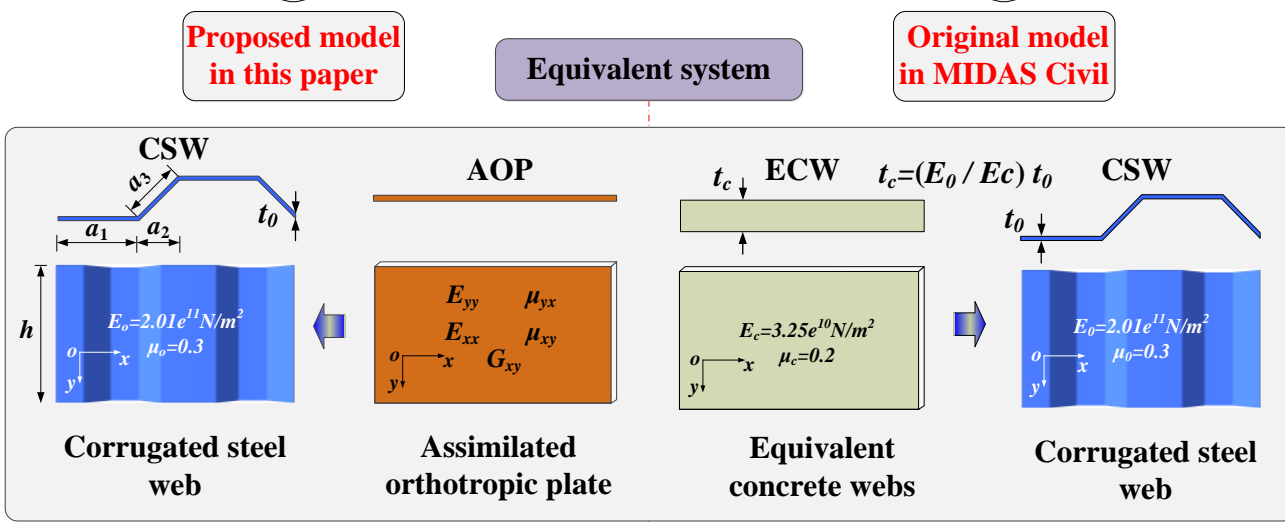

\section{Constitutive relation}

Elasticity modulus:

$E_{x x}=\lambda\left(t_{0} / h\right)^{2} E_{0} ; E_{y y}=\frac{\left(a_{1}+a_{3}\right)}{\left(a_{1}+a_{2}\right)} E_{0}$

Poisson's ratio :

$\mu_{y x}=\mu_{0} ; \mu_{x y}=\frac{E_{x x}}{E_{y y}} \mu_{0}$

Shear modulus :

$G_{x y}=\frac{\left(a_{1}+a_{3}\right)}{\left(a_{1}+a_{2}\right)} G_{0}$

Density :

$\left.\rho\right|_{A O P}=\rho_{0}$ (density of steel)

\section{Elasticity modulus:}

$\left.E\right|_{E C W}=E_{c}$ (concrete elastic modulus)

Poisson's ratio :

$\left.\mu\right|_{E C W}=\mu_{c}$ (concrete elastic modulus)

\section{Shear modulus :}

$\left.G\right|_{E C W}=G_{c}($ concrete shear modulus $)$

\section{Density :}

$\left.\rho\right|_{E C W}=\rho_{c}($ density of cncrete $)$

Sectional properties

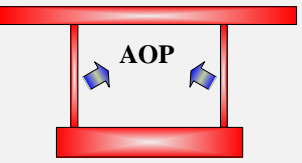

Effective shear area

Effect shear area: $A$-the area of cross-section

Moments of Inertia : $I_{c}$-Moment of inertia of flanges

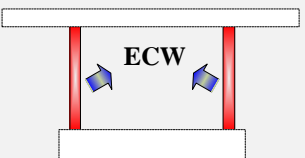

Effective shear area

Effect shear area : $A_{\mathrm{s}}$-the area of ECW

Moments of Inertia: $I_{c}$-Moment of inertia of flanges

\section{Element matrix}

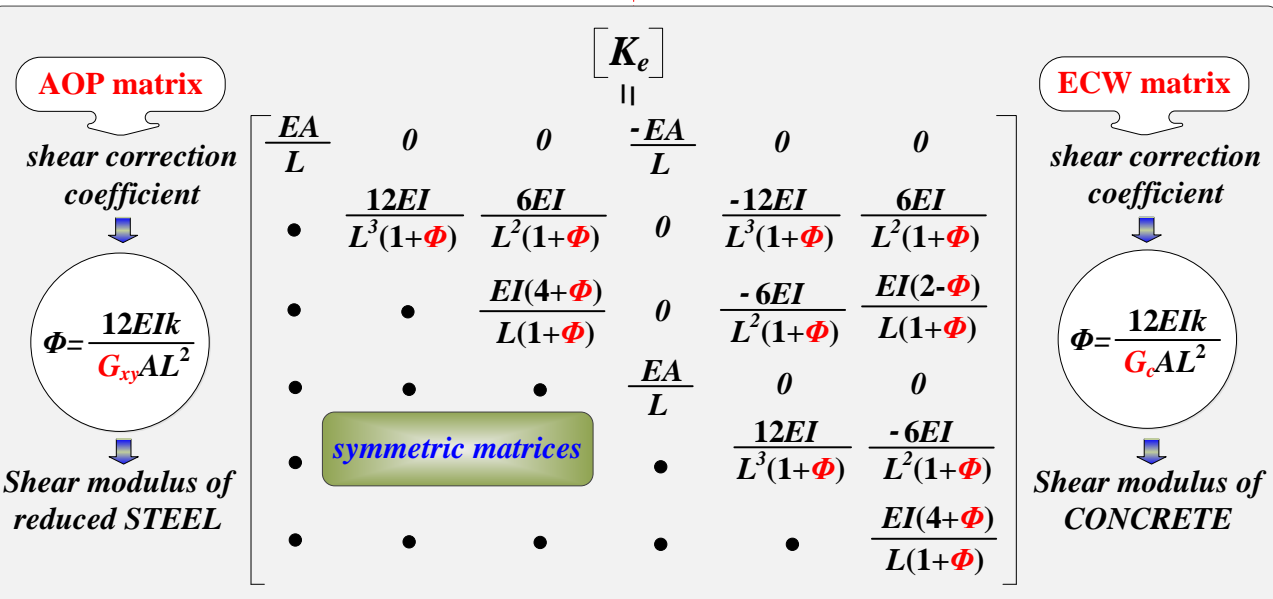




\section{Conclusions}

Based on the results of this study, the following conclusions are drawn.

(1) The flat ECW model is used to replace the folded CSWs in MIDAS Civil. This equivalent model cannot provide good estimations for the shear stress and deflection of box girders with CSWs. The study demonstrates that the shear stress calculated using the ECW model of the spatial beam elements is approximately $35.6 \%$ of the result obtained using the CSW solid model in ABAQUS (the ECWs are nearly six-times thicker than the CSWs based on the conversion considering the elastic moduli of steel and concrete), even though the ECWs are assumed to bear all vertical shear force in the section. The total deformation obtained from MIDAS Civil is approximately $26.4 \%$ greater than the actual deformation under gravity; moreover, the shear deformation caused by the self-weight is approximately $52.7 \%$ greater than the accurate values duo to the shear-bearing capacity of the concrete flanges being neglected.

(2) An improved analysis model that can better indicate the structural performance of orthotropic properties, namely, the AOP model (the effective elastic parameter equations are derived in Eq. (1) $\sim$ Eq. (12)), is established to improve the computational efficiency and accuracy of the CSWs. In addition to greatly simplifying the complex simulation modeling, the numerical analysis indicates that the stress and deformation calculated using the AOP model are in agreement with the results calculated using the CSW model. The authors suggest that MIDAS IT Co. should adopt the AOP model instead of the original ECW model to improve the analysis module for this type of bridge.

(3) A new method, which approximately calculates the bending deformation of the non-prismatic box girder with CSWs, is proposed based on Castigliano's Second Theorem and Simpson Integration. A non-prismatic box girder with CSWs is made equivalent to a prismatic beam by introducing the concept of the equivalent inertia moment of the variable cross section, thus avoiding the complicated integration process when the inertia moment is a function of the integration variable. Therefore, this approach has provided unified bending deformation formulas for a beam with varying sections or equal sections.

(4) In this paper, the authors deduced a formula for the deflection caused by shear distortion in non-prismatic box girders with CSWs by considering the factors of variable cross-section, the shear bearing capacity of the concrete flanges and the accordion effects of the corrugated sheets. The conventional assumption that shear deformation is mainly caused by shear flow of the webs is proved to be improper for non-prismatic girders with CSWs. The additional shear deformation caused by bending should also be considered. The authors decomposed the shear deformation of the folded web and concrete flanges subjected to combined moment and shear using the derived analytical formulas and found that the shear deformation of the concrete flange is sufficiently small to be neglected, and the shear deformation mainly results from the corrugated sheets loaded with the combined shear and moment.

(5) A practical experiment was conducted on a bridge during construction to verify the accuracy of the theoretical formulas for the stress and deflection of non-prismatic box girders with CSWs. By comparing the analytical results with the measured data and the FEM numerical calculations, the derived formulas were shown to be sufficiently accurate for engineering applications. 


\section{Acknowledgment}

This work was sponsored by the National Science Foundation of China (51478107 and 51578479). Thanks to Dr. Erdal Atrek for providing valuable comments.

\section{References}

[1] Jiang R, Au F, Xiao Y. Prestressed concrete girder bridges with corrugated steel webs: A Review. J Struct Eng, ASCE 2014;141(2):1-8.

[2] Liu Y, Composite structure bridge (In Chinese). Beijing: China Communication Press 2004:85-94.

[3] Hamilton R. Behavior of welded girders with corrugated webs. Doctoral thesis, University of Maine; 1993.

[4] Elgaaly M, Hamilton R, Seshadri A. Shear strength of beams with corrugated webs. J Struct Eng, ASCE 1996;122(4):390-398.

[5] Luo R, Edlund B. Shear capacity of plate girders with trapezoidally corrugated webs. Thin Wall Struct 1996;26(1):19-44.

[6] Höglund T. Shear buckling resistance of steel and aluminium plate girders. Thin Wall Struct 1997;29(1):13-30.

[7] Sayed-Ahmed E. Behaviour of steel and (or) composite girders with corrugated steel webs. Can J Civil Eng 2001;28(4):656-672.

[8] Driver R, Abbas H, Sause R. Shear behavior of corrugated web bridge girders. J Struct Eng, ASCE 2006;132(2):195-203.

[9] Ibrahim S A, El-Dakhakhni W W, Elgaaly M. Behavior of bridge girders with corrugated webs under monotonic and cyclic loading. Eng Struct 2006; 28(14): 1941-1955.

[10] Nguyen N D, Kim S N, Han S R, Kang Y J. Elastic lateral-torsional buckling strength of I-girder with trapezoidal web corrugations using a new warping constant under uniform moment. Eng Struct 2006; 32(8):2157-2165.

[11] Abbas H H, Sause R, Driver R G. Simplified analysis of flange transverse bending of corrugated web I-girders under in-plane moment and shear. Eng Struct 2007;29(11):2816-2824.

[12] Yi J, Gil H, Youm K, Lee H. Interactive shear buckling behavior of trapezoidally corrugated steel webs. Eng Struct 2008;30(6):1659-1666.

[13] Moon J, Yi J, Choi B, Lee H. Shear strength and design of trapezoidally corrugated steel webs. J Constr Steel Res 2009;65(5):1198-1205.

[14] Kim K S, Lee D H, Choi S M, Choi Y H, Jung S H. Flexural behavior of prestressed composite beams with corrugated web: Part I. Development and analysis. Compos Part B-Eng, 2011; 42(6):1603-1616.

[15] Sause R, Braxtan T N. Shear strength of trapezoidal corrugated steel webs. J Constr Steel Res 2011; 67(2): 223-236.

[16] Barakat S, Al Mansouri A, Altoubat S, Shear strength of steel beams with trapezoidal corrugated webs using regression analysis. Steel Compos Struct 2015;18(3):757-773.

[17] Hassanein M, Kharoob O. Shear buckling behavior of tapered bridge girders with steel corrugated webs. Eng Struct 2014;4:157-169.

[18] Zevallos E, Hassanein MF, Real E, Mirambell E. Shear evaluation of tapered bridge girder panels with steel corrugated webs near the supports of continuous bridges. Eng Struct 2016;113:149-159.

[19] Johnson R, Cafolla J, Bernard C. Corrugated webs in plate girders for bridges. Proc ICE-Str B 1997;122(2):157-164. 
[20] Shitou K, Nakazono A, Suzuki N. Experimental research on shear behavior of corrugated steel web bridge. J Japan Society Civil Eng 2008;64(2):223-234.

798 [21] Machimdamrong C, Watanabe E, Utsunomiya T. An extended elastic shear deformable beam theory and its application to corrugated steel web girder. J Struct Eng, ASCE 2003;49:29-38.

800 [22] He J, Liu Y, Chen A, Wang, Q. Deflection calculation of composite girder bridge with corrugated 801 steel web with consideration of shear deformation. J Tongji Univ 2009;37(4):440-444.

802 [23] Atrek E. Non-Linear finite element analysis of light Gage steel shear diaphragms. New York: 803 Doctoral thesis, Department of Structural Engineering School of Civil and Environmental Engineering, 804 Cornell University; 1976.

805 [24] Zhou M, Zhang JD, Zhong JT, Zhao Y. Shear stress calculation and distribution in variable cross 806 sections of box girders with corrugated steel webs (Accepted). J Struct Eng, ASCE 2016.

807 [25] Fujioka A., Kakuta T. Application of the corrugated steel webs to PCT-girder bridge: Sou river 808 bridge. Proc., 6th Symp. Hybrid Struct, 2005; 1-8 (in Japanese).

809 [26] Wu W Q, Ye J S, Wan S. Quasi plane assumption and its application in steel-concrete composite 810 box girders with corrugated steel webs. Eng. Mech., 2005;22(5), 177-180 (in Chinese). 